\title{
Tighten the Bolts and Nuts on GPP Estimations from Sites to the Globe: An Assessment of Remote Sensing Based LUE Models and Supporting Data Fields
}

\author{
Zhao Wang ${ }^{1,2}$, Shuguang Liu ${ }^{1,2, *}$, Ying-Ping Wang ${ }^{3}$, Ruben Valbuena ${ }^{4} \oplus$, Yiping Wu $5 \oplus$, Mykola Kutia $4,6 \oplus$, \\ Yi Zheng ${ }^{7}$, Weizhi Lu ${ }^{1,2}$, Yu Zhu ${ }^{1,2}$, Meifang Zhao ${ }^{1,2}$, Xi Peng ${ }^{1,2}$, Haiqiang Gao ${ }^{1,2}$, Shuailong Feng ${ }^{1,2}$ \\ and Yi Shi ${ }^{1,2}$ \\ 1 College of Life Science and Technology, Central South University of Forestry and Technology, \\ Changsha 410004,China; 20181100139@csuft.edu.cn (Z.W.); weizhilu@csuft.edu.cn (W.L.); \\ koxinga_zhu@csuft.edu.cn.com (Y.Z.); t20131447@csuft.edu.cn.com (M.Z.); 20180100029@csuft.edu.cn (X.P.); \\ 20200100045@csuft.edu.cn (H.G.); 20200100032@csuft.edu.cn (S.F.); 20200100044@csuft.edu.cn (Y.S.) \\ 2 National Engineering Laboratory for Applied Technology of Forestry \& Ecology in South China, \\ Changsha 410004, China \\ 3 CSIRO Oceans and Atmosphere, 107 Station Street, Aspendale, Victoria 3195, Australia; \\ Yingping.Wang@csiro.au \\ 4 School of Natural Sciences, Thoday Building, Deiniol Road, Bangor University, Gwynedd, LL57 2UW, UK; \\ r.valbuena@bangor.ac.uk (R.V.); m.kutia@bangor.ac.uk (M.K.) \\ 5 Department of Earth and Environmental Science, School of Human Settlements and Civil Engineering, \\ Xi'an Jiaotong University, Xi'an 710049, China; yipingwu@xjtu.edu.cn \\ 6 Bangor College China, Bangor University, 498 Shaoshan Rd., Changsha 410004, China \\ 7 School of Atmospheric Sciences, Sun Yat-sen University, Guangzhou 510245, China; \\ zhengy263@mail2.sysu.edu.cn \\ * Correspondence: Shuguang.liu@csuft.edu.cn
}

Citation: Wang, Z.; Liu, S.; Wang, Y.-P.; Valbuena, R.; Wu, Y.; Kutia, M.; Zheng, Y.; Lu, W.; Zhu, Y.; Zhao, M.; et al. Tighten the Bolts and Nuts on GPP Estimations from Sites to the Globe: An Assessment of Remote Sensing Based LUE Models and Supporting Data Fields. Remote Sens. 2021, 13, 168. https://doi.org/ $10.3390 /$ rs13020168

Received: 14 November 2020 Accepted: 31 December 2020 Published: 6 January 2021

Publisher's Note: MDPI stays neutral with regard to jurisdictional clai$\mathrm{ms}$ in published maps and institutional affiliations.

Copyright: (C) 2021 by the authors. Licensee MDPI, Basel, Switzerland. This article is an open access article distributed under the terms and conditions of the Creative Commons Attribution (CC BY) license (https:// creativecommons.org/licenses/by/ $4.0 /)$.
Abstract: Gross primary production (GPP) determines the amounts of carbon and energy that enter terrestrial ecosystems. However, the tremendous uncertainty of the GPP still hinders the reliability of GPP estimates and therefore understanding of the global carbon cycle. In this study, using observations from global eddy covariance (EC) flux towers, we appraised the performance of 24 widely used GPP models and the quality of major spatial data layers that drive the models. Results show that global GPP products generated by the 24 models varied greatly in means (from

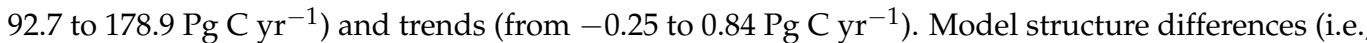
light use efficiency models, machine learning models, and process-based biophysical models) are an important aspect contributing to the large uncertainty. In addition, various biases in currently available spatial datasets have found (e.g., only $57 \%$ of the observed variation in photosynthetically active radiation at the flux tower locations was explained by the spatial dataset), which not only affect GPP simulation but more importantly hinder the simulation and understanding of the earth system. Moving forward, research into the efficacy of model structures and precision of input data may be more important for global GPP estimation.

Keywords: gross primary production; eddy covariance; constraint model precision; remote sensing products biases

\section{Introduction}

Terrestrial gross primary production (GPP) or the total photosynthetic uptake of carbon by plants plays a critical role in maintaining the global carbon balance between the biosphere and atmosphere. However, the estimation of terrestrial GPP by existing models remains highly uncertain, with global estimates ranging widely between 92.7

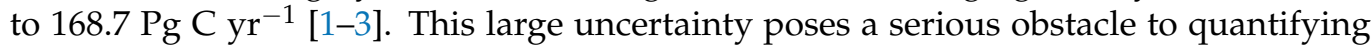
and understanding the global carbon cycle [4]. It is broadly agreed that, to reduce the 
uncertainty of GPP estimation and advance carbon cycle science, it is crucial to consider: (1) The impacts of model structure, (2) the determination of parameter values, and (3) the quality of data feeding in GPP models $[5,6]$.

Model structure is considered one of the most important factors that affect model performance $[7,8]$. Yet, large structural differences can be observed among GPP models. For example, the fraction of photosynthetic active radiation (FPAR), an important parameter in the light use efficiency (LUE) models, has been treated in disparate ways, either approximated by the enhanced vegetation index (EVI) in the vegetation photosynthesis model (VPM) [9], as a linear function of normalized difference vegetation index (NDVI) in the eddy covariance-light use efficiency (EC-LUE) model [10], or as a nonlinear function of leaf area index (LAI) according to Beer's Law, among others [11]. A similar situation exists for representing temperature stress (TS), water stress (WS), and their interactions among models. The moderate resolution imaging spectroradiometer (MODIS) model and the VPM model adopt a multiplicative structure to represent the collective influences of WS and TS on GPP [7,12]. The EC-LUE model, on the other hand, considers that the Liebig's law is ecologically more reasonable in representing the effects of WS and TS [9].

The estimation of model parameters often affect the simulation accuracy of the model, thus rigorous model parameterization and calibration should be adopted in GPP modeling [13]. Variation in the values of the same biophysical parameters among different models is a major concern in GPP estimation. For example, the maximum light use efficiency (LUE(max)), a parameter used in LUE-based GPP models, represents the maximum efficiency of unit vegetation converting energy to photosynthates and therefore should be relatively stable [14]. However, it has taken many different values in LUEbased GPP models. In the MODIS model, LUE(max) values are biome-specific, varying from 0.604 to $1.259 \mathrm{~g} \mathrm{C} \mathrm{MJ}^{-1}$ (Running et al., 2006), and similar approaches can be found in other models [15]. The EC-LUE model, on the other hand, takes a constant value at $\operatorname{LUE}(\max )=2.25 \mathrm{~g} \mathrm{C} \mathrm{MJ}^{-1}$, that was derived from many flux tower observations, and the authors later advocated the use of different constant LUE(max) values for C3 and C4 plants [16]. However, another study has suggested that a fixed LUE(max) value would lead to increased GPP uncertainty [17]. An analysis of the parameters of the diagnostic carbon flux model (DCFM) showed that cross-site estimation improved the representativeness and robustness of parameter estimates [18]. Studies considering a wider number of flux towers are thus necessary for a more reliable tuning of GPP model parameters.

Regional to global simulations inevitably employ spatiotemporal data for initialization or as driving forces [19]. How spatial data products affect GPP simulation has rarely been assessed because users of the data products tend to take a leap of faith by assuming the quality of data has met the accuracy requirement and limited findings regarding the importance of data quality have been ignored frequently. For example, it was found that the widely used average of eight-days MODIS satellite FPAR data was unable to effectively reflect the reality [20]. Other studies have revealed that MODIS satellite FPAR products are systematically lower than ground-measured FPAR observations in winter and spring [21]. Clouds seriously affect satellite observations in humid regions such as the Amazon [22]. Even when applying a cloud correction by the CFMask algorithm [23] only $70 \%$ of PAR can be satisfactorily simulated [24]. Failure to reproduce the driving data of the models faithfully would affect the simulation and accuracy of GPP.

To address the three issues mentioned above and improve the estimation accuracy of GPP at a global scale, we comprehensively appraised the structure and performance of existing LUE models against GPP estimates from 151 eddy covariance (EC) flux towers worldwide, and assessed the impacts of using currently available data products on the estimates of global GPP using newly developed LUE models. The specific objectives were to: (1) Compare existing models and address model structure deficiency, if necessary, (2) find the optimal parameter values using GPP observed at the EC towers, (3) develop a new model to taking advantage of remote sensing (RS) data as directly as possible, reducing errors of intermediate data products and algorithms, (4) evaluate errors of spatial RS data 
and their impacts on GPP estimation, and (5) generate a new GPP model and subsequent global product, after correcting biases in spatial data layers.

\section{Materials and Methods}

In this study, using observations from global EC flux towers, we appraised 8 common satellite-data-based GPP models and the quality of major spatial data layers that drive the models. In order to utilize remote sensing data as directly as possible and minimize error propagation, 2 new GPP models were developed and compared with the 8 common satellite-data-based GPP models. Finally, 24 existing global GPP products, including the global GPP product generated from the new model that showed better performance, were compared and analyzed for similarity and differences.

\subsection{Description of Existing GPP Models Used in this Study and the New Models}

A total of 8 common satellite-data-based GPP models and 22 global GPP products were included in this study. The 8 existing models were the eddy covariance-light use efficiency (EC-LUE) model [9], the vegetation-indices (VI) model [25], the temperaturegreenness (TG) model [26], the vegetation photosynthesis model (VPM) [11], the carbon fixation model (CFIX) model [27], the greenness-radiation (GR) model [28], the alpine vegetation (AVM) model [29], and the moderate resolution imaging spectroradiometer (MODIS) model [30]. At the site scale, we reproduced the 8 common satellite-data-based GPP models and compared them with the two new models in this study.

The two new models were adaptations of the EC-LUE model, which included corrections for cloudiness and $\mathrm{CO}_{2}$ concentration, with two derivations for determining water stress: One from the evaporative fraction (i.e., the LUE-EF model) and another from the normalized difference water index (NDWI) (i.e., the LUE-NDWI model), as described below.

\subsection{Description of the LUE-EF Model}

This model was developed mainly based on the principles of the EC-LUE model [9]. Specifically, the regulation of water on GPP is represented by the evaporative fraction (EF), taking advantage of the newly available EF products [31]. In addition, two new modifiers of GPP were added to the original EC-LUE model. The first modifier considers the impact of cloudiness on GPP. The other modifier addresses the fertilization effect of increased $\mathrm{CO}_{2}$ concentration in the atmosphere.

The LUE-EF model can be expressed as follows:

$$
G P P=P A R \times F P A R \times F_{C I} \times F_{C O 2} \times L U E_{(M A X)} \times \min \left(T_{S}, W_{S}\right)
$$

where PAR is incident photosynthetic active radiation $\left(\mathrm{MJ} / \mathrm{m}^{2}\right)$ over a period of time; FPAR is the fraction of PAR absorbed by the vegetation; $F_{C I}$ is the regulation of cloudiness on GPP; $F_{C O 2}$ is the regulation scalar of atmospheric $\mathrm{CO}_{2}$ concentration; $L U E_{(M A X)}$ is the maximum light use efficiency; and $T_{S}$ and $W_{S}$ are regulation scalars respectively for temperature and water stress on GPP, from which the minimum value is taken, following the Leibig law [9], and the expression of Ts is the same as that of EC-LUE model. The determination of model parameters was done as:

1. FPAR is in practice approximated by EVI [11], since photosynthetically active vegetation is estimated as a ratio $\alpha$ of EVI, set to be $\alpha=1$ :

$$
F P A R_{E V I}=\alpha \times E V I
$$

2. Most previous models underestimates of GPP on cloudy days mainly because photosynthesis can be increased by diffuse radiation under cloudy conditions [6,32]. The regulating effect of cloud cover on GPP was expressed by a cloudiness index (CI) as follow:

$$
F_{C I}=a \times C I+b
$$


where CI is the ratio of PAR to potential PAR (PPAR) [6], and PPAR is PAR that reaches the upper atmosphere. Using the FLUXNET2015 dataset, the coefficients were determined to be $\mathrm{a}(=2.9)$ and $\mathrm{b}(=1.2)$;

3. For calculating the influence of atmospheric $\mathrm{CO}_{2}$ on GPP, we employed the algorithm in the Frankfurt Biosphere Model (FBM):

$$
F_{C O 2}=f(C O 2, T)=\frac{C C L-\Delta(T)}{C C L+2 \Delta(T)}
$$

where $C C L$ is the internal $\mathrm{CO}_{2}$ concentration of leaves, and it assumed to be $70 \%$ of atmospheric $\mathrm{CO}_{2}$ concentration [33]. $\Delta(T)$ is the $\mathrm{CO}_{2}$ compensation point for gross photosynthesis and photorespiration at temperature $T\left({ }^{\circ} \mathrm{C}\right)[34]$ :

$$
\Delta(T)=40.6 e^{\frac{(9.46 \times(T-25))}{(T+273.2)}} ;
$$

4. The regulation scalar of water on GPP, $W_{S}$, was expressed as the evaporative fraction $(E F)$ of the total sensible and latent heat [9]:

$$
W_{S}=E F=\frac{L E}{L E+H}
$$

where $L E$ is latent heat flux $\left(\mathrm{W} \mathrm{m}^{-2}\right)$, and $H$ is sensible heat flux $\left(\mathrm{W} \mathrm{m}^{-2}\right)$.

\subsection{Description of the LUE-NDWI Model}

The LUE-NDWI model can be expressed as follows:

$$
G P P=P A R \times F P A R \times F_{C I} \times F_{C O 2} \times L U E_{(M A X)} \times \min \left(T_{S}, W_{S_{-} N D W I}\right) .
$$

It can be seen that the only difference between LUE-EF and LUE-NDWI is the expression for water stress. The NDWI, strongly related to vegetation water content [35,36], can be a very good proxy for vegetation water stress. In addition, NDWI data can be obtained through satellite observation directly and the EF obtained by calculating sensible heat and latent heat, cannot be directly observed. After examining measurements from many flux towers, we found that the following nonlinear function can be used to represent $W_{S}$, the regulation scalar of water stress on GPP, using NDWI:

$$
W_{S \_N D W I}=a *(-N D W I+0.5)^{b}+\mathrm{c} .
$$

Using the 'nls' method of parameter optimization adjustment, the coefficients were determined to be a $(=0.35), \mathrm{b}(=2.14)$, and $\mathrm{c}(=0.086)$. The $W_{S_{-N} N W I}$ values vary between 0 and 1 , with values beyond the bounds set to 0 or 1 , respectively. The use of $W_{S \_N D W I}$ can be very convenient for applications from local to global scales as the NDWI fields can be directly derived from satellite observations.

\subsection{Data for Evaluation of Models and Spatial Data Products}

For an evaluation of models and remotely sensed data products, we used eddy covariance (EC) flux tower data from the FLUXNET2015 dataset (https: / fluxnet.fluxdata. org) [37]. Our study included data from 151 EC tower sites that belonged to the following 12 terrestrial biomes: Croplands (CRO), closed Shrublands (CSH), deciduous broadleaf forest (DBF), deciduous needleleaf forest (DNF), evergreen broadleaf forest (EBF), evergreen needleleaf forest (ENF), grasslands (GRA), mixed forests (MF), open shrublands (OSH), savannas (SAV), permanent wetlands (WET), and woody savannas (WSA). We used two criteria to filter the data, following [6]: (1) If more than $20 \%$ of the data in a given year was missing, the whole year was discarded, and (2) after this first step of processing, EC-tower sites with records for less than two years were completely discarded. EC-towers details are in Table A1. 
To simulate global GPP, the following spatial data products were used: (1) Meteorological data fields-radiation, air temperature, latent heat flux, and sensible heat fluxderived from the second Modern-Era Retrospective analysis for Research and Applications (MERRA-2), (2) MODIS satellite products including enhanced vegetation index (EVI) and normalized difference wetness index (NDWI), and (3) global atmospheric $\mathrm{CO}_{2}$ concentration product from the Earth System Research Laboratory Global Monitoring Division (https://www.esrl.noaa.gov/gmd/dv/site/).

\subsection{Evaluation of Spatial Data Products and Model Performance}

In this study, data from FLUXNET eddy covariance flux tower sites were retained for analysis after data quality control. Half of the EC-towers were used for model calibration and the other half for validation. Values of model parameters were estimated using the Gauss-Newton algorithm for nonlinear optimization as implemented in the 'nls' function in the R language (package 'stats' v3.6.1) [38]. The model uncertainty at the site scale was assessed using correlation coefficient (r), normalized root-mean-square error (RMSE), and standard deviation (SD) of predicted and observed values, displayed by the Taylor diagrams. In addition, the ability to capture temporal changes of GPP is essential for GPP models. The double mass curve (cumulative GPP predicted by model versus cumulative GPP observed at EC-towers) computed per site can reflect the ability of models to simulate the temporal changes of GPP, and the percentage bias (PB) of each site was counted [39].

It is critical that spatial data fields used to drive these models should represent the site-level conditions with high accuracy when these models are applied to estimate GPP at regional to global scales. In this study, the accuracy of spatial data products were evaluated against measurements collected at the flux tower sites. Specifically, orthogonal regressions were performed, comparing each of the spatial data products against their corresponding site-level measurements [40]. Their 1:1 correspondence and biases was assessed by a hypothesis tests $(\alpha=0.05)$ of the regression coefficients, with null hypothesis being slope $=1$ and intercept $=0$ [41]. Orthogonal regression can take into account the errors of both the independent and dependent variables at the same time [42]. These analyses were conducted using the 'scipy.stats' and 'odr' packages in Python (v3) [43]. When generating global GPP products, the spatial data layers (i.e., uncorrected datasets) of driving variables were corrected according to the correction coefficients obtained at the site scale through orthogonal regression. The correction coefficients were the slope and intercept of linear regression between variable values measured at the flux towers and their equivalent from the spatial datasets.

Finally, we evaluated a total of 24 global GPP products: Two from this study (LUENDWI with uncorrected and corrected spatial datasets, respectively), and 22 products from TRENDY (http:/ /dgvm.ceh.ac.uk/) [44] and other studies [3]. Specifically, the 22 global GPP products were EC-LUE, revised EC-LUE [6], MODIS [25], MOD17 C6 [45], PR [46], VPM [11], FLUXCOM-ANN, FLUXCOM-MARS, and FLUXCOM-RF from FLUXCOM [47], SVR [48], BESS [49], BEPS [50], and 10 TRENDY products. The performance of the LUE-EF model was not evaluated at a global scale because of the difficulty in estimating the water stress in the LUE-EF model (i.e., the evaporative fraction of net solar radiation), which cannot be readily derived from satellite observations. We analyzed the similarity and differences of the GPP products in magnitude, spatial patterns, and temporal trends.

\section{Results}

\subsection{Comparison of Model Performance at the Site Scale}

Globally among all the 10 models evaluated, the LUE-EF model had the highest correlation coefficient of $r=0.86$, followed by the LUE-NDWI model with $r=0.82$ (Figure 1a). The LUE-EF model had the smallest normalized RMSE (0.50), indicating that the difference between the LUE-EF model and EC-tower GPP was the smallest among all models. The LUE-NDWI model had the second smallest normalized RMSE (0.52). The normalized RMSE for the other models was larger than the two new models. Model LUE-EF simulated 
the amplitude of the variations close to the data amplitude of EC-towers (SD ratio $=0.93$ ). When grouped by latitudinal zone (Figure $1 \mathrm{~b}-\mathrm{e}$ ) the improvements of the new models were more apparent for tropical and northern temperate zones. In the temperate zones, the distribution of models in the Taylor diagram was relatively concentrated, whereas in the tropical and boreal areas there were larger differences among models. When grouped by biome (Figure A1), the new LUE-EF model showed advantages of fit in simulating daily GPP for most biomes, both in terms of correlation coefficients and RMSE. For example, correlation coefficients were highest for LUE-EF in deciduous broadleaved and evergreen needleleaf forests, wetlands, and grasslands (DBF, ENF, WET, and GRA), with LUE-NDWI being the second highest in the latter three of those. It is important to note that these biomes also have the largest number of EC-towers. It is relevant to note that many biomes are underrepresented in the current EC-tower network, such as closed shrublands or deciduous needle-leaved forests (CSH and DNF), each represented by only one and two EC-towers. The Taylor diagram shows that the models in CSH, DNF, and SAV are more dispersed, which means that model performances in these biomes vary greatly.
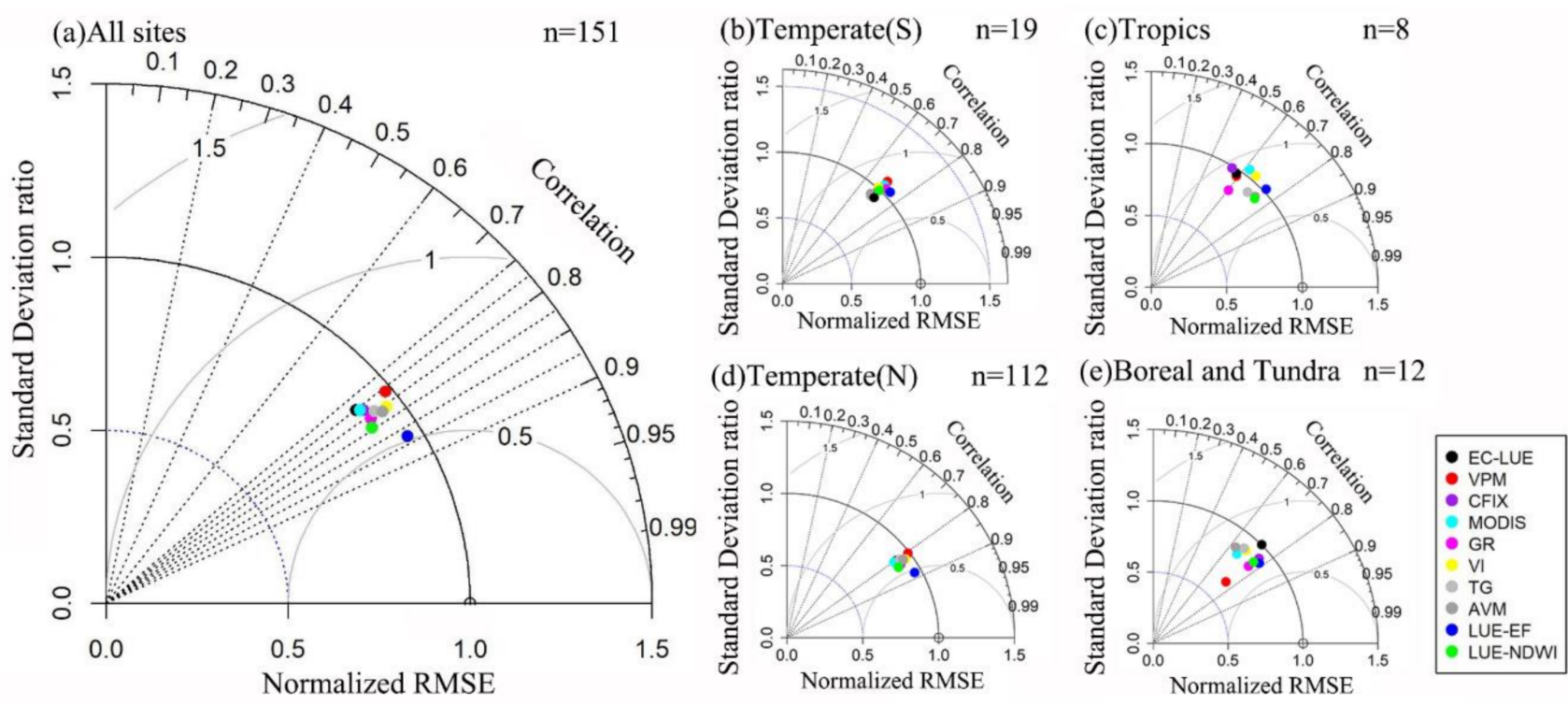

Figure 1. The Taylor diagram showing (a) the performance of all models, data from eddy covariance (EC) towers were used.; $(\mathbf{b}-\mathbf{e})$ the performance of all models in different latitudinal geographical zones (tropics: $-23.5^{\circ}-23.5^{\circ}$, temperate:-23.5 $-\left(-66.5^{\circ}\right)$ and $\left(23.5^{\circ}-66.5^{\circ}\right)$, boreal and tundra: $\left.66.5^{\circ}-90^{\circ}\right)$, where $\mathrm{N}$ and $\mathrm{S}$ represent the Northern and Southern hemispheres, respectively. The upper right corner of subplot " $n$ " is number of EC-towers.

The distribution of double mass curves (Figure 2) show that those of the LUE-EF were the most concentrated around the 1:1 correspondence line among the 10 models compared, which indicates its greater ability to simulate the patterns in temporal variability of GPP. Figure 2 also shows the distributions of relative bias in ratio (PB-percentage biases), which ranged \pm 0.4 for all models, indicating that the models had a large heterogeneity (i.e., the PB of each EC-tower is quite different) in simulating the temporal change of GPP across sites. The biases were however narrower for the LUE-EF and LUE-NDWI models, respectively, containing 120 and 110 of the EC-towers within \pm 0.2 in their PB, the largest number of EC-towers amongst all models. In contrast, the number of sites with $\mathrm{PB} \pm 0.2$ did not exceed 100 sites for each of the other models. This indicates that the two new models had a stronger ability to capture the spatial (smaller dispersion of the double mass curves) and temporal (smaller deviation of the double mass curve from the 1:1 reference line) changes of GPP. 


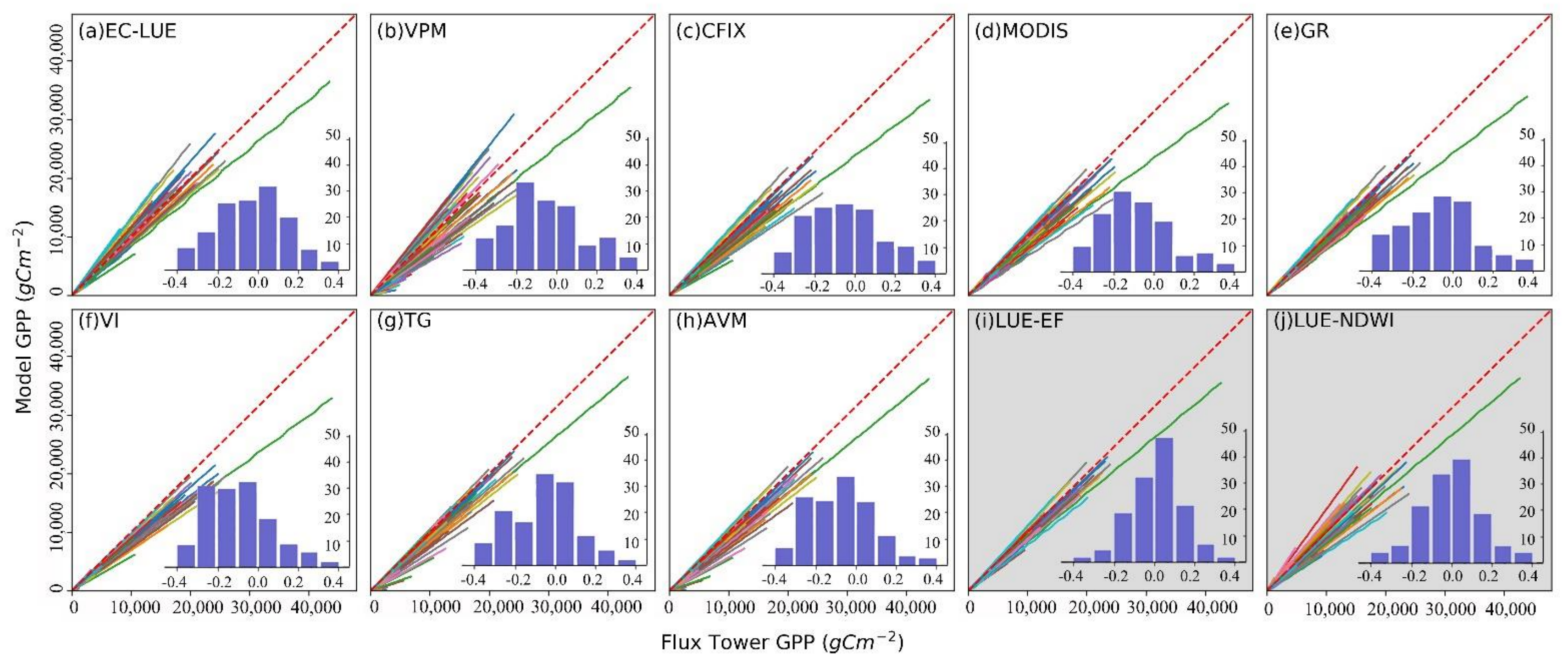

Figure 2. Comparison of cumulative gross primary production (GPP) estimates from the flux towers and the models. The color lines represent the GPP value of cumulative comparison between the EC-tower and model for each site. The red dashed line is the 1:1 reference to the differences of modeled GPP and EC-tower. Inset histogram shows the frequency distribution of the percentage biases (PB) at the flux towers. The two shaded plots (panels i and $\mathrm{j}$ ) are two new models devel-oped in this study. (a) EC-LUE (eddy covariance-light use efficiency model), (b) VPM (vegetation photosynthesis model), (c) CFIX (carbon fixation model), (d) MODIS (moderate resolution imaging spectroradiometer model), (e) GR (green-ness-radiation model), (f) VI (vegetation-indices model), (g) TG (temperature-greenness model), (h) AVM (alpine vegetation model), (i) LUE-EF (light use efficiency-evaporative fraction model), (j) LUE-NDWI (light use efficiency-normalized difference water index model).

\subsection{Biases in Remote Sensing Data Products and Consequences on Global GPP Estimation}

First, various biases were found when the spatial datasets that feed the models for global GPP simulations were evaluated at the site scale (Figures 3 and A2). For example, the spatial PAR dataset only explained $57 \%$ of the observed PAR variation at the EC-towers, and the slope and intercept were 1.2 and 0.57 , respectively, indicating that the PAR data fields overestimated PAR as a whole and slightly underestimated PAR at the low value. The determination coefficients of the global datasets of $\mathrm{CO}_{2}, \mathrm{LE}$, and $\mathrm{H}$ at the EC-towers were less than $20 \%\left(R^{2}<0.2\right)$, and only temperature data was efficient in representing site-scale variation $\left(R^{2}=0.89\right)$.

Second, the biases in the spatial datasets had a significant impact on GPP simulations was found through orthogonal regression. Before correcting these biases, the simulated GPP by the LUE-EF and LUE-NDWI models explained only $49 \%$ and $61 \%$ of the EC-tower GPP variation, and the slopes of the linear regression between simulated and towerestimated GPP were 1.54 and 1.31, respectively, and the corresponding intercepts were -2.09 and -1.23 . These results indicate that both models overestimated GPP as a whole, but underestimated low GPP values (Figure $3 b, f$ ). After correcting the biases in the spatial datasets, the $\mathrm{R}^{2}$ of LUE-EF and LUE-NDWI models improved to 0.80 and 0.79 , with the slopes closer to 1 (1.20 and 1.18 values, respectively) and the intercepts closer to 0 ( -0.59 and -0.91 , respectively) (Figure 3c,g). The results also indicated that the LUE-NDWI model was less sensitive to the biases in the spatial data fields than the LUE-EF model, as shown by the smaller differences in $\mathrm{R}^{2}$ before and after data correction. This can probably be attributed to the fact that the LUE-NDWI relies on NDWI, a factor that can be derived directly from remote sensing data and thereby less prone to error propagation than the LUE-EF model. 

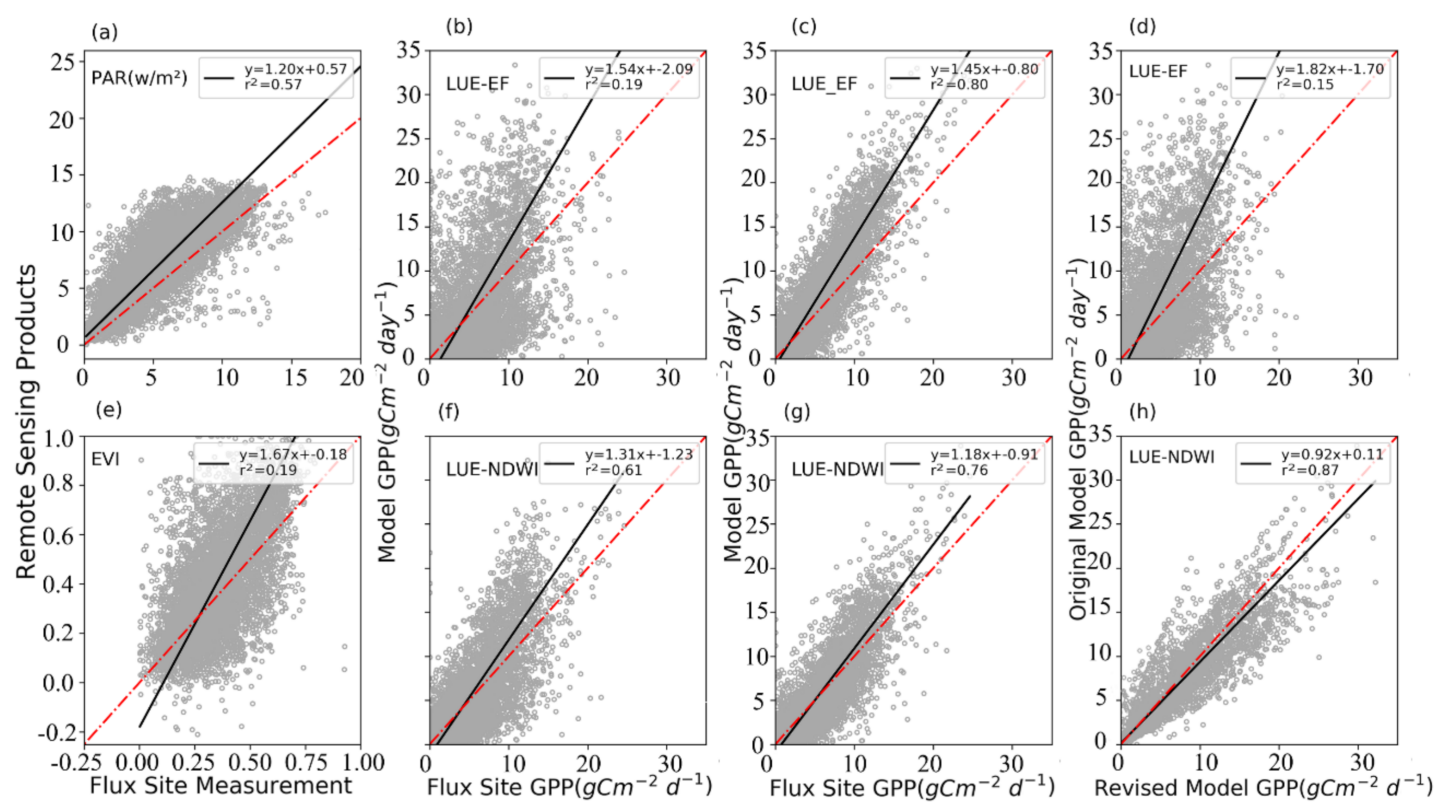

Figure 3. Comparison of (a) spatial PAR (photosynthetic active radiation) and site PAR, (b) tower GPP and LUE-EF GPP (uncorrected spatial data), (c) tower GPP and LUE-EF GPP (corrected spatial data), (d) LUE-EF GPP with uncorrected and LUE-EF GPP corrected spatial data, (e) spatial EVI (500 m resolution) and spatial EVI (10 km resolution), (f) tower GPP and LUE-NDWI GPP (uncorrected spatial data), (g) tower GPP and LUE-NDWI GPP (corrected spatial data), and (h) LUE-NDWI GPP with uncorrected and LUE-NDWI GPP corrected spatial data. All comparisons are based on site scale. Corrected spatial data were generated from the uncorrected ones after correcting their biases using orthogonality regression (see Section 2.5).

At a global scale, the biases in spatial data inputs had a great impact on the simulated GPP even for the less sensitive model LUE-NDWI. Figure 4a shows the global average annual GPP distribution from 2000 to 2018, simulated by the LUE-NDWI model using corrected input data layers. The spatial pattern of GPP agrees well with previous studies. However, the impact of data biases on the spatial pattern of simulated GPP was obvious and not uniform across space (Figure $4 \mathrm{~b}$ ). The area overestimated is much larger than the underestimated area when the data biases were not attended, and the area fractions with GPP biases at $(-50 \%)-(-30 \%),(-30 \%)-(-10 \%), 10-30 \%$, and $30-50 \%$, were $8 \%, 19 \%, 27 \%$, $31 \%$, and $15 \%$, respectively. After data correction, the area of GPP serious reduction occurs in the mountain systems of the Tibetan plateau in Asia, northern Africa, and South America region. Growth trends of GPP were observed in Australia, northwest North America, and Siberia. The global annual average GPP estimated by the LUE-NDWI, after input data

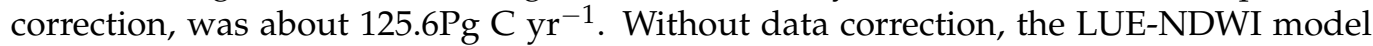
would overestimate global GPP by $18 \%$ (Figure $5 a, b$ ). The corresponding global growth rate of GPP decreased from 0.34 to $0.17 \mathrm{Pg} \mathrm{C} \mathrm{yr}^{-1}$ after input data correction (Figure $5 \mathrm{c}$ ). 
(a)

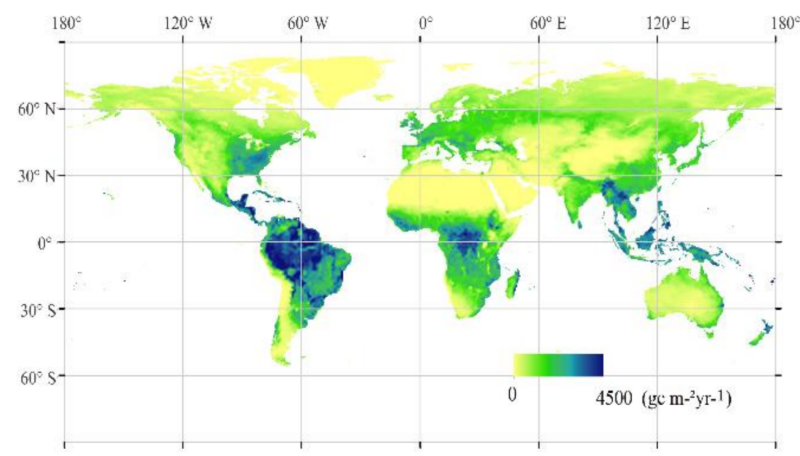

(b)

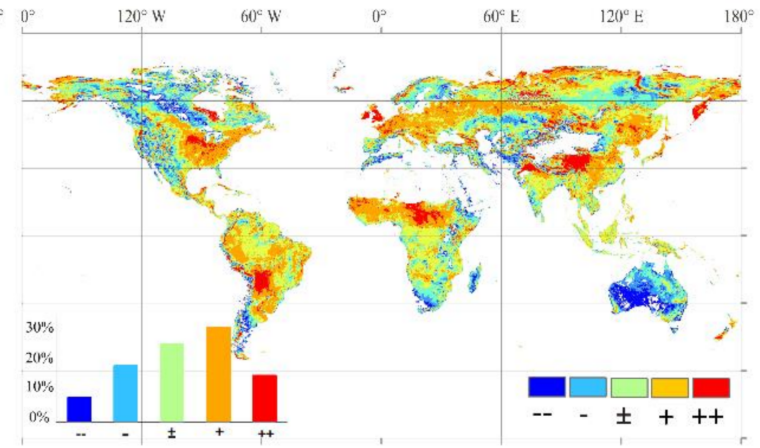

Figure 4. Consequences of biased input data on LUE-NDWI GPP at a global scale. (a) The mean annual GPP from 2000 to 2018 after data correction (reference Section 2.5). (b) The difference of mean annual GPP from 2000 to 2018, GPPuncorrectedGPPcorrected. Symbols indicate various levels of difference: '-': $-50 \%-(-30 \%),-^{\prime}:-30 \%-(-10 \%), \pm^{\prime}:-10 \%-10 \%$, '+': $10-30 \%$, , $^{\prime}+$ ': $30-50 \%$. The inset bar chart shows the global distribution of the difference proportions.

(a)

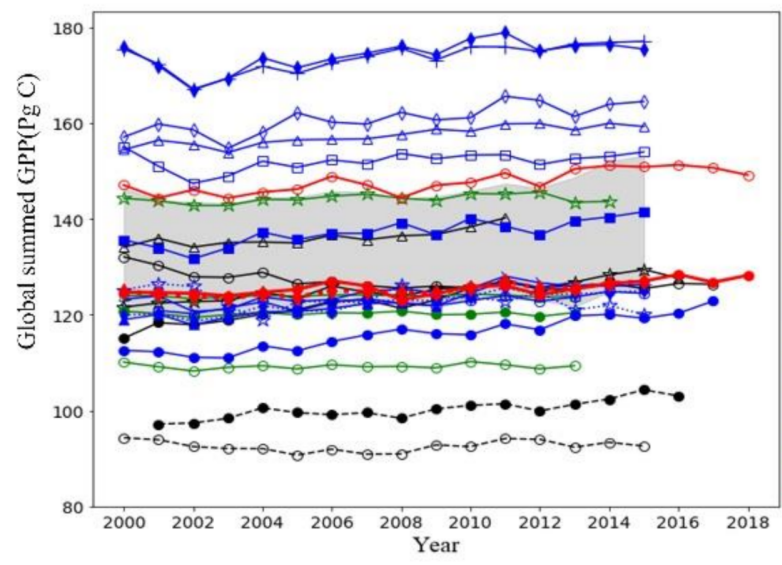

(b)

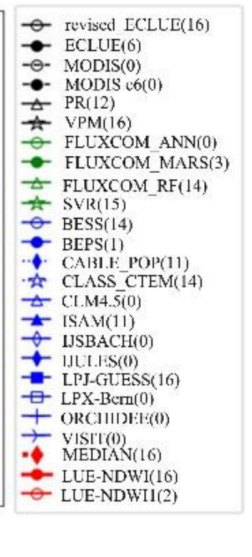

(c)

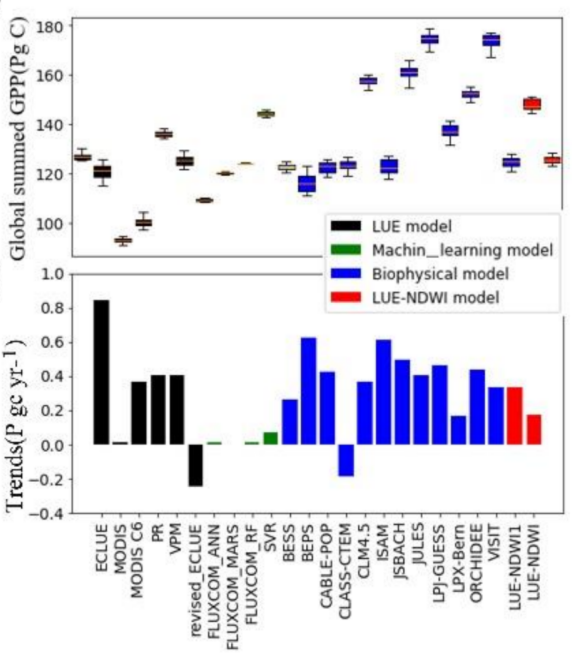

Figure 5. (a) Comparison of annual global GPP estimates from various models. The number after each model's name in parentheses is the model's number of years in the interquartile range (IQR) of all global GPP products, indicated by the shaded region. LUE-NDWI (data corrected) and LUE-NDWI1(i.e., LUE-NDWI with spatial data uncorrected) are GPP estimated by LUE-NDWI with corrected and uncorrected input data, respectively. (b) Boxplot of annual GPP values during

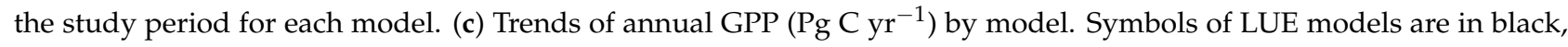
machine learning models in green, and biophysical models in blue.

\subsection{Comparison of 24 Global GPP Products}

A comparison of 24 global GPP products is shown in Figure 5a. Large differences can be seen from these models with long-term GPP averages varying from 92.7 to 178.9 $\mathrm{Pg} \mathrm{C} \mathrm{yr}^{-1}$, with more GPP estimates concentrated in the range of $120-130 \mathrm{Pg} \mathrm{C} \mathrm{yr}^{-1}$ (Figure $5 \mathrm{a}, \mathrm{b}$ ). The number of times that a model's GPP stays within the interquartile range (IQR) of all 24 GPP products throughout the years can be used as an indicator of model performance. Result showed that the annual GPP values simulated by the following models stayed within their annual IQRs every year: Revised_ECLUE, VPM, SVR, LPJ_GUESS, and LUE-NDWI (after correcting input data biases), suggesting a better performance in simulating GPP. Although not in the category above, FLUXCOM RF, BESS, CABLE POP, and CLASS CTEM models have more than 10 years in IQR. It is worth noting that the GPP 
from the LUE-NDWI model, after data correction, was the closest to the median GPP value of the 24 global models.

The interannual variabilities simulated by these models were also quite different (Figure 5b). The interannual variabilities of LUE and biophysical models were generally higher than the machine learning models as shown by their standard deviation or std: ECLUE (std = 2.96 Pg C yr $\left.{ }^{-1}\right)$, BEPS ( $\left.\mathrm{std}=3.51 \mathrm{Pg} \mathrm{C} \mathrm{yr}^{-1}\right), \mathrm{JSBACH}\left(\mathrm{std}=2.97 \mathrm{Pg} \mathrm{C} \mathrm{yr}^{-1}\right)$,

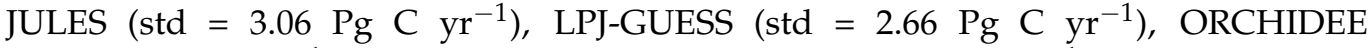
$\left(\mathrm{std}=2.91{\left.\mathrm{PgC} \mathrm{yr}^{-1}\right)}\right.$, FLUXCOM_ANN (std $\left.=0.53 \mathrm{Pg} \mathrm{C} \mathrm{yr}^{-1}\right)$, FLUXCOM_RF $\left(\mathrm{std}=0.38 \mathrm{Pg} \mathrm{C} \mathrm{yr}^{-1}\right)$, and FLUXCOM_MARS (std $\left.=0.23 \mathrm{Pg} \mathrm{C} \mathrm{yr}^{-1}\right)$. The standard deviation of LUE-NDWI (after correcting input data biases) model was $1.83 \mathrm{Pg} \mathrm{C} \mathrm{yr}^{-1}$, close to the mean standard (1.68 $\mathrm{Pg} \mathrm{C} \mathrm{yr}^{-1}$ ) of all the models within the IQR range.

The trends of GPP simulated by the 24 models also varied greatly from -0.25 to $0.84 \mathrm{Pg} \mathrm{C} \mathrm{yr}^{-1}$ (Figure 5c). The trends of the machine learning models were smaller than those of other models. Most models showed positive trends, only the revised-ECLUE and CLASS-CTEM models showed downward trends, and some models demonstrated no significant trends (i.e., MODIS, FLUXCOM_ANN, FLUXCOM_MARS, and FLUXCOM_RF).

\section{Discussion}

\subsection{Adequacy of Model Structure in Representing Processes}

The understanding of the processes involved in GPP is fundamental to building a reliable GPP model. For example, we found that a failed incorporation of the effect of clouds on GPP in some existing models significantly underestimated GPP in areas with frequent cloudy cover (Figure A1). Under clear sky conditions, the upper canopy leaves are close to light saturation, while the lower canopy leaves are shaded and have limited light [51]. In contrast, under cloudy conditions, a higher proportion of the light in the form of diffuse radiation can reach the lower parts of the canopy, thus increasing the total photosynthetic use of PAR by vegetation [31]. Some studies indicated that a $1 \%$ increase in diffuse radiation induces a $0.94 \%$ increase in GPP $[27,28]$. In addition, many studies have shown that $\mathrm{CO}_{2}$ fertilization has a significant effect on vegetation production, a dominant factor contributing to the 31\% increase in global GPP since 1990 [52,53]. Nevertheless, many LUE models have not explicitly accounted for the effect of increasing atmospheric $\mathrm{CO}_{2}$ concentration [6,31]. In our study, after incorporating the impacts of both cloud cover and $\mathrm{CO}_{2}$, the performance of the LUE-EF and LUE-NDWI models improved compared with the original EC-LUE model: $\mathrm{R}^{2}$ improved from 0.61 to 0.68 for LUE-NDWI and from 0.61 to 0.74 for LUE-EF, respectively.

Water availability is an important factor that affects GPP [13]. In this study, we adopted two alternative structural expressions to represent the impact of water stress on GPP. First, the evaporative fraction (EF) of total energy, closely related to the Bowen ratio, was used in the LUE-EF model. The relevance of LUE-EF is grounded in the fact that less energy used for ecosystem evaporation (i.e., smaller evaporative fraction) implies a stronger water limitation [33], which has largely been verified using flux tower measurements [54]. Nevertheless, the application of the LUE-EF model is hindered by the derivation of EF that required multiple steps and input data layers and is therefore prone to error propagation [55]. In order to get a direct measure of water stress and therefore minimize error propagation, from satellite observations we replaced the EF using NDWI in the LUE-NDWI model, based on the evidence that NDWI is closely related to the plant water content and thus a good proxy for plant water stress [56]. The direct use of NDWI in the LUE-NDWI model makes it ideal for mapping GPP on regional to global scales.

\subsection{Input Data Biases and Possible Impacts on GPP Simulations}

Evaluating the quality of input data and understanding the impact of data biases on GPP simulation are prerequisites for improving GPP simulation accuracy. In this study, we found that the data from the spatial data fields at the EC-tower sites had various systematic deviations that seriously affected GPP estimates. For example, the spatial data fields of 
PAR explained only $57 \%$ of the PAR variation observed at the EC-tower sites. Reasons for the data biases are mainly rooted in the influence of sensor errors and atmospheric factors (e.g., cloud and snow) $[50,57,58]$. In addition, attempts unifying data from different spatial and temporal resolutions also bring biases as we found that data at different resolutions sometimes had poor correlations. The reason for the existence of resolution mismatch (i.e., spatial product data pixels cannot be unified in temporal or spatial scale) is mainly caused by mixed pixels and/or different time scales (e.g., daily, eight-day, or monthly data), compared to the spatio-temporal resolution that applies to ground conditions [51,59]. In general, spatial data biases are an important cause of the uncertainty of GPP simulation, which is an important reason for the large differences in GPP estimated among existing GPP models [60,61].

A comparison of existing global GPP products shows a huge variation from 92.7 to 178.9 $\mathrm{Pg} \mathrm{C} \mathrm{yr}^{-1}$, which is not only affected by input data biases, but also by the model structure $[13,62]$. One should realize that input data biases affect the model outputs differently, depending on the model structure. In our study, it was found that the LUE-EF model is more susceptible to data errors, while the LUE-NDWI model is less affected by data biases (Figure 3d). The sensitivities of the GPP models to data deviations should be systematically investigated in future research as the sensitivities have not been effectively evaluated and compared.

\subsection{Improving GPP Simulation Capability: The Ways Forward}

A reduction in model complexity and error accumulation should be a major consideration in improving GPP estimation. For example, the evaporative fraction parameter of the LUE-EF model involves more steps than the direct use of NDWI from satellite in the LUE-NDWI model, and consequently the risk of the error accumulation increases. The direct observation and continuous recording of NDWI as a remote sensing product is one of the main advantages of the LUE-NDWI model, which minimizes the risk of error propagation of the LUE-NDWI model at a regional to global scale. Therefore, the LUE-NDWI model is more practical and attractive in spatially-explicit simulations of GPP. In summary, the simple forms of GPP models and widely and readily available inputs, as compared with more complex global models, make them more practical for applications over large areas and better suited for attribution and uncertainty analysis $[53,63]$.

Vastly different GPP products, as shown by the means, trends, and interannual variabilities of GPP, generated by the 24 models suggest our current ability in simulating global GPP is not encouraging (Figure 5a). For nearly 40 years of commitment to the global simulation of GPP, there does not seem to have a clear direction of improvement in GPP estimation as shown by the vast differences among GPP models in simulating global GPP. GPP model development is not explicitly directed, despite the constant emergence of new models. Our research indicates that both the structures of the models and input data are error prone. Therefore, it is necessary to optimize model structures as well as sufficient validation and calibration of the input data to improve GPP simulation.

\section{Conclusions}

In this study, we first developed two new GPP models, driven by convenient remote sensing data and climate variables, with an emphasis on the representations of GPP responses to cloud, $\mathrm{CO}_{2}$, and water stress. Then, the performances of the new models along with other commonly used GPP models were appraised using GPP estimates from global eddy covariance (EC) flux towers. The quality of major spatial data layers that drive the models at the global scale was also evaluated at the EC-towers.

Two new models (LUE-EF and LUE-NDWI) showed advantages in simulating daily GPP for most biomes. Meanwhile, they had a stronger ability in capturing the spatial and temporal changes of GPP and the improvements of the new models were more apparent for tropical and northern temperate zones. Then, a new global GPP product was generated using the LUE-NDWI model. The LUE-EF model was not applied on a global scale because 
of the difficulty in estimating the water stress in the LUE-EF model (i.e., the evaporative fraction of net solar radiation), which cannot be readily derived from satellite observations.

Various biases were found in the spatial datasets that feed the models, affecting the simulation of GPP from site to global scales. Addressing these biases is a high priority for earth system science. In addition, large differences were found from 24 global models with long-term GPP averages varying from 92.7 to $178.9 \mathrm{Pg} \mathrm{C} \mathrm{yr}^{-1}$. The newly developed LUE-NDWI model (after correcting input data biases) produced a global mean annual GPP that is very close to the mean level of all the models within the inter-quantile range of GPP from all 24 models. Moving forward, a reduction in model complexity and error accumulation, validation, and calibration of the input data fields are key processes of improving GPP simulation.

The newly developed new remote sensing-based GPP model had excellent performance and could be used to estimate GPP across a range of scales. Improving the quality of input data fields should be a major research component in reducing the uncertainty in GPP simulations on regional to global scales. The existent biases of spatial data not only affect GPP simulation but more importantly hinder the simulation and understanding of the earth system. Effective correction of spatial data is critical for reducing the uncertainty in GPP simulations and research on improving data quality should be encouraged. In this regard, our research cautions using currently available spatial data for relevant research.

Author Contributions: All the authors have made a substantial contribution towards the successful completion of this manuscript. All authors have read and agreed to the published version of the manuscript.

Funding: This research was funded by the National Natural Science Foundation of China (Grant No. 41971152); and the Hunan Innovative Talent Program (Grant No. 2019RS1062) to S Liu.

Data Availability Statement: The data presented in this study are openly available in FigShare at https:/ / figshare.com/s/2462e5dc7cc3203a044c.

Acknowledgments: We thank the anonymous reviewers for their valuable comments. We gratefully acknowledge FLUXNET, NASA, and NOAA for providing the data that were used in this study. The covariance data used in the study was acquired and shared by the FLUXNET community, CO2 data from Earth System Research Laboratory Global Monitoring Division (https:/ /www.esrl.noaa.gov/), and the mete-orological data from the second Modern-Era Retrospective analysis for Research and Applications (MERRA-2).

Conflicts of Interest: We declare that we have no financial and personal relationships with other people or organizations that can inappropriately influence our work, there is no professional or other personal interest of any nature or kind in any product, service, and/or company that could be construed as influencing the position presented in, or the review of, the manuscript entitled, "Tighten the bolts and nuts on GPP estimations from sites to the globe: An assessment of LUE models and supporting data fields".

\section{Appendix A}

Existing models have estimation bias for GPP under different cloud cover conditions, and cloud cover index can adjust this phenomenon (Figure A3). Under mostly cloudy conditions, it can be found that the overall distribution of PB in all models is biased to the negative side, which indicates that the model underestimates GPP under mostly cloudy conditions. Under partly cloudy conditions, the existing models PB is more evenly distributed around the unbiased line, yet systematically giving lower values of GPP than on clear days. Some models are more affected than others by this cloudiness-induced bias, with VPM, VI, and GR models being those most affected by GPP underestimation on cloudy days, whereas other models had less overall deviation. In order to improve model performances, the cloudiness correction factor (Equation (3)) dependent on cloud cover index (CI) was added and compared with the original model. We found that the cloudiness factor clearly improved GPP prediction for most models, except for GR, MODIS, and AVM models, which showed no obvious improvements. For example, the original MODIS model 
underestimates GPP under partly cloudy and mostly cloudy conditions, with no obvious deviation under sunny conditions. However, after adding CI, GPP underestimates appear under all three cloud cover conditions.

Comparing the fitting performance of the models at different scales can reflect the ability of the model to reflect spatio-temporal changes (Table 2). As expected, the $\mathrm{R}^{2}$ of the model was larger on the coarser spatio-temporal scales. On one hand, for the same time scale, the $\mathrm{R}^{2}$ of the biome scale was higher than that of the site scale. Similarly, for a same spatial scale, the $\mathrm{R}^{2}$ were increasingly larger from the daily, yearly, and to the scale of many years. This indicates that the model captures the spatial and temporal variation of GPP, but the capture capability is different. In addition to the biome_years scale, the $\mathrm{R}^{2}$ of the LUE-NDWI model was 0.94 less than VPM model, and the $\mathrm{R}^{2}$ of the LUE-EF and LUE-NDWI models were higher than that of other models. It can be seen that two new modes had advantages in capturing spatial and temporal changes. Second, on the scale of site_year, the slope of LUE-EF and LUE-NDWI models was 1 and extremely significant ( $p_{-}$value $\left.<0.01\right), \mathrm{R}^{2}$ was also higher, 0.85 and 0.75 ( $p_{-}$value $<0.05$ ), indicating that the LUE-EF and LUE-NDWI models explained $85 \%$ and $75 \%$, respectively, of the EC-tower GPP. In addition, the slope of LUE-NDWI model in site_years was also 1 ( $p$-value $<0.01$, indicating that the model had the optimal simulation effect on these scales, that is, the applicability of the model was the most reliable.

Table A1. Eddy covariance (EC) sites information used for research, including site id (ID), site name (SITE), latitude and longitude (LAT, LON), and biome type (BIO). The asterisk is used to verify the model.

\begin{tabular}{|c|c|c|c|c|}
\hline ID & SITE & LAT & LON & BIO \\
\hline 1 & BE-Lon & 50.5516 & 4.7461 & $\mathrm{CRO}^{*}$ \\
\hline 2 & DE-Seh & 50.8706 & 6.4497 & CRO \\
\hline 3 & FI-Jok & 60.8986 & 23.5135 & CRO \\
\hline 4 & IT-CA2 & 42.3772 & 12.026 & $\mathrm{CRO}^{*}$ \\
\hline 5 & US-CRT & 41.6285 & -83.347 & $\mathrm{CRO}^{*}$ \\
\hline 6 & US-Lin & 36.3566 & -119.84 & CRO \\
\hline 7 & US-Tw3 & 38.1159 & -121.65 & CRO \\
\hline 8 & US-Twt & 38.1087 & -121.65 & $\mathrm{CRO}^{*}$ \\
\hline 9 & US-ARM & 36.6058 & -97.489 & $\mathrm{CRO}^{*}$ \\
\hline 10 & US-Ne2 & 41.1649 & -96.47 & CRO \\
\hline 11 & US-Ne3 & 41.1797 & -96.44 & CRO \\
\hline 12 & DE-Kli & 50.8931 & 13.5224 & $\mathrm{CRO}$ \\
\hline 13 & FR-Gri & 48.8442 & 1.9519 & $\mathrm{CRO}^{*}$ \\
\hline 14 & US-Ne1 & 41.1651 & -96.477 & $\mathrm{CRO}^{*}$ \\
\hline 15 & IT-Noe & 40.6062 & 8.1512 & $\mathrm{CSH}$ \\
\hline 16 & US-KS2 & 28.6086 & -80.672 & $\mathrm{CSH}^{*}$ \\
\hline 17 & CA-Oas & 53.6289 & -106.2 & DBF \\
\hline 18 & CA-TPD & 42.6353 & -80.558 & $\mathrm{DBF}$ \\
\hline 19 & DE-Hai & 51.0792 & 10.453 & $\mathrm{DBF}^{*}$ \\
\hline 20 & DK-Sor & 55.4859 & 11.6446 & $\mathrm{DBF}^{*}$ \\
\hline 21 & FR-Fon & 48.4764 & 2.7801 & DBF \\
\hline 22 & IT-CA1 & 42.3804 & 12.0266 & $\mathrm{DBF}^{*}$ \\
\hline 23 & IT-CA3 & 42.38 & 12.0222 & $\mathrm{DBF}$ \\
\hline 24 & IT-Col & 41.8494 & 13.5881 & DBF \\
\hline 25 & IT-Isp & 45.8126 & 8.6336 & $\mathrm{DBF}^{*}$ \\
\hline 26 & IT-Ro1 & 42.4081 & 11.93 & $\mathrm{DBF}$ \\
\hline 27 & IT-Ro2 & 42.3903 & 11.9209 & DBF \\
\hline 28 & PA-SPn & 9.3181 & -79.635 & $\mathrm{DBF}^{*}$ \\
\hline 29 & US-Ha1 & 42.5378 & -72.172 & $\mathrm{DBF}^{*}$ \\
\hline 30 & US-MMS & 39.3232 & -86.413 & $\mathrm{DBF}^{*}$ \\
\hline 31 & US-Oho & 41.5545 & -83.844 & DBF \\
\hline 32 & US-UMB & 45.5598 & -84.714 & $\mathrm{DBF}^{*}$ \\
\hline 33 & US-UMd & 45.5625 & -84.698 & DBF \\
\hline
\end{tabular}


Table A1. Cont.

\begin{tabular}{|c|c|c|c|c|}
\hline ID & SITE & LAT & LON & BIO \\
\hline 34 & US-WCr & 45.8059 & -90.08 & DBF \\
\hline 35 & ZM-Mon & -15.438 & 23.2528 & $\mathrm{DBF}^{*}$ \\
\hline 36 & RU-SkP & 62.255 & 129.168 & DNF \\
\hline 37 & AU-Cum & -33.615 & 150.724 & $\mathrm{EBF}^{*}$ \\
\hline 38 & AU-Tum & -35.657 & 148.152 & EBF \\
\hline 39 & AU-Wac & -37.426 & 145.188 & $\mathrm{EBF}^{*}$ \\
\hline 40 & AU-Whr & -36.673 & 145.029 & $\mathrm{EBF}^{*}$ \\
\hline 41 & AU-Wom & -37.422 & 144.094 & $\mathrm{EBF}$ \\
\hline 42 & BR-Sa1 & -2.8567 & -54.959 & $\mathrm{EBF}$ \\
\hline 43 & BR-Sa3 & -3.018 & -54.971 & EBF * \\
\hline 44 & FR-Pue & 43.7413 & 3.5957 & $\mathrm{EBF}^{*}$ \\
\hline 45 & GF-Guy & 5.2788 & -52.925 & EBF \\
\hline 46 & IT-Cp2 & 41.7043 & 12.3573 & EBF \\
\hline 47 & IT-Cpz & 41.7053 & 12.3761 & EBF \\
\hline 48 & MY-PSO & 2.973 & 102.306 & $\mathrm{EBF}$ \\
\hline 49 & AU-ASM & -22.283 & 133.249 & $\mathrm{ENF}^{*}$ \\
\hline 50 & CA-NS1 & 55.8792 & -98.484 & ENF \\
\hline 51 & CA-NS2 & 55.9058 & -98.525 & ENF \\
\hline 52 & CA-NS3 & 55.9117 & -98.382 & ENF * \\
\hline 53 & CA-NS4 & 55.9144 & -98.381 & ENF \\
\hline 54 & CA-NS5 & 55.8631 & -98.485 & ENF \\
\hline 55 & CA-Obs & 53.9872 & -105.12 & $\mathrm{ENF}^{*}$ \\
\hline 56 & CA-Qfo & 49.6925 & -74.342 & ENF \\
\hline 57 & CA-SF1 & 54.485 & -105.82 & ENF \\
\hline 58 & CA-SF2 & 54.2539 & -105.88 & $\mathrm{ENF}^{*}$ \\
\hline 59 & CA-TP1 & 42.6609 & -80.56 & ENF \\
\hline 60 & CA-TP2 & 42.7744 & -80.459 & $\mathrm{ENF}^{*}$ \\
\hline 61 & CA-TP3 & 42.7068 & -80.348 & ENF \\
\hline 62 & CA-TP4 & 42.7102 & -80.357 & $\mathrm{ENF}^{*}$ \\
\hline 63 & CH-Dav & 46.8153 & 9.8559 & $\mathrm{ENF}^{*}$ \\
\hline 64 & CZ-BK1 & 49.5021 & 18.5369 & ENF \\
\hline 65 & DE-Lkb & 49.0996 & 13.3047 & $\mathrm{ENF}^{*}$ \\
\hline 66 & FI-Let & 60.6418 & 23.9595 & ENF \\
\hline 67 & FR-LBr & 44.7171 & -0.7693 & $\mathrm{ENF}^{*}$ \\
\hline 68 & IT-La2 & 45.9542 & 11.2853 & ENF \\
\hline 69 & IT-Ren & 46.5869 & 11.4337 & $\mathrm{ENF}^{*}$ \\
\hline 70 & IT-SR2 & 43.732 & 10.291 & $\mathrm{ENF}^{*}$ \\
\hline 71 & RU-Fyo & 56.4615 & 32.9221 & ENF \\
\hline 72 & US-Blo & 38.8953 & -120.63 & ENF \\
\hline 73 & US-GBT & 41.3658 & -106.24 & $\mathrm{ENF}^{*}$ \\
\hline 74 & US-GLE & 41.3665 & -106.24 & $\mathrm{ENF}^{*}$ \\
\hline 75 & US-Me2 & 44.4523 & -121.56 & ENF \\
\hline 76 & US-Me3 & 44.3154 & -121.61 & ENF \\
\hline 77 & US-Me5 & 44.4372 & -121.57 & ENF * \\
\hline 78 & US-Me6 & 44.3233 & -121.61 & ENF \\
\hline 79 & US-NR1 & 40.0329 & -105.55 & $\mathrm{ENF}^{*}$ \\
\hline 80 & US-Prr & 65.1237 & -147.49 & $\mathrm{ENF}^{*}$ \\
\hline 81 & US-Wi4 & 46.7393 & -91.166 & ENF \\
\hline 82 & US-Wi9 & 46.6188 & -91.081 & $\mathrm{ENF}^{*}$ \\
\hline 83 & AT-Neu & 47.1167 & 11.3175 & GRA * \\
\hline 84 & AU-DaP & -14.063 & 131.318 & GRA * \\
\hline 85 & AU-Emr & -23.859 & 148.475 & GRA * \\
\hline 86 & AU-Rig & -36.65 & 145.576 & GRA \\
\hline 87 & $\mathrm{CH}-\mathrm{Cha}$ & 47.2102 & 8.4104 & GRA * \\
\hline 88 & CH-Fru & 47.1158 & 8.5378 & GRA \\
\hline 89 & CH-Oe1 & 47.2858 & 7.7319 & GRA \\
\hline 90 & CN-Cng & 44.5934 & 123.509 & GRA * \\
\hline 91 & CN-Dan & 30.4978 & 91.0664 & GRA * \\
\hline 92 & CN-Du2 & 42.0467 & 116.284 & GRA \\
\hline 93 & CN-HaM & 37.37 & 101.18 & GRA \\
\hline 94 & CZ-BK2 & 49.4944 & 18.5429 & GRA * \\
\hline
\end{tabular}


Table A1. Cont.

\begin{tabular}{|c|c|c|c|c|}
\hline ID & SITE & LAT & LON & BIO \\
\hline 95 & DE-Gri & 50.95 & 13.5126 & GRA \\
\hline 96 & DK-Eng & 55.6905 & 12.1918 & GRA * \\
\hline 97 & $\mathrm{DK}-\mathrm{ZaH}$ & 74.4733 & -20.55 & GRA \\
\hline 98 & IT-Tor & 45.8444 & 7.5781 & GRA \\
\hline 99 & PA-SPs & 9.3138 & -79.631 & GRA * \\
\hline 100 & RU-Ha1 & 54.7252 & 90.0022 & GRA * \\
\hline 101 & RU-Tks & 71.5943 & 128.888 & GRA \\
\hline 102 & US-AR1 & 36.4267 & -99.42 & GRA \\
\hline 103 & US-AR2 & 36.6358 & -99.598 & GRA * \\
\hline 104 & US-ARb & 35.5497 & -98.04 & GRA \\
\hline 105 & US-ARc & 35.5465 & -98.04 & GRA * \\
\hline 106 & US-Cop & 38.09 & -109.39 & GRA \\
\hline 107 & US-Goo & 34.2547 & -89.874 & GRA \\
\hline 108 & US-IB2 & 41.8406 & -88.241 & GRA * \\
\hline 109 & US-SRG & 31.7894 & -110.83 & GRA * \\
\hline 110 & US-Var & 38.4133 & -120.95 & GRA \\
\hline 111 & US-Wkg & 31.7365 & -109.94 & GRA * \\
\hline 112 & BE-Bra & 51.3076 & 4.5198 & MF \\
\hline 113 & BE-Vie & 50.305 & 5.9981 & $\mathrm{MF}^{*}$ \\
\hline 114 & CA-Gro & 48.2167 & -82.156 & MF \\
\hline 115 & CN-Cha & 42.4025 & 128.096 & $\mathrm{MF}^{*}$ \\
\hline 116 & US-Syv & 46.242 & -89.348 & $\mathrm{MF}$ \\
\hline 117 & CA-NS6 & 55.9167 & -98.964 & $\mathrm{OSH}^{*}$ \\
\hline 118 & CA-NS7 & 56.6358 & -99.948 & $\mathrm{OSH}^{*}$ \\
\hline 119 & CA-SF3 & 54.0916 & -106.01 & $\mathrm{OSH}$ \\
\hline 120 & ES-Amo & 36.8336 & -2.2523 & $\mathrm{OSH}$ \\
\hline 121 & ES-LgS & 37.0979 & -2.9658 & $\mathrm{OSH}^{*}$ \\
\hline 122 & US-SRC & 31.9083 & -110.84 & $\mathrm{OSH}^{*}$ \\
\hline 123 & US-Whs & 31.7438 & -110.05 & $\mathrm{OSH}$ \\
\hline 124 & AU-Dry & -15.259 & 132.371 & SAV \\
\hline 125 & AU-GWW & -30.191 & 120.654 & SAV * \\
\hline 126 & CG-Tch & -4.2892 & 11.6564 & SAV * \\
\hline 127 & SD-Dem & 13.2829 & 30.4783 & SAV \\
\hline 128 & SN-Dhr & 15.4028 & -15.432 & SAV * \\
\hline 129 & ZA-Kru & -25.02 & 31.4969 & SAV * \\
\hline 130 & AU-Fog & -12.545 & 131.307 & WET \\
\hline 131 & CN-Ha2 & 37.6086 & 101.327 & WET * \\
\hline 132 & CZ-wet & 49.0247 & 14.7704 & WET \\
\hline 133 & DE-Akm & 53.8662 & 13.6834 & WET \\
\hline 134 & DE-SfN & 47.8064 & 11.3275 & WET * \\
\hline 135 & DE-Spw & 51.8923 & 14.0337 & WET \\
\hline 136 & DE-Zrk & 53.8759 & 12.889 & WET \\
\hline 137 & DK-NuF & 64.1308 & -51.386 & WET * \\
\hline 138 & $\mathrm{DK}-\mathrm{ZaF}$ & 74.4814 & -20.555 & WET \\
\hline 139 & FI-Lom & 67.9972 & 24.2092 & WET * \\
\hline 140 & SE-St1 & 68.3542 & 19.0503 & WET \\
\hline 141 & US-Atq & 70.4696 & -157.41 & WET * \\
\hline 142 & US-Ivo & 68.4865 & -155.75 & WET * \\
\hline 143 & US-Los & 46.0827 & -89.979 & WET \\
\hline 144 & US-Myb & 38.0498 & -121.77 & WET \\
\hline 145 & US-Tw1 & 38.1074 & -121.65 & WET * \\
\hline 146 & US-WPT & 41.4646 & -82.996 & WET \\
\hline 147 & AU-Gin & -31.376 & 115.714 & WSA \\
\hline 148 & AU-How & -12.494 & 131.152 & WSA * \\
\hline 149 & AU-RDF & -14.564 & 132.478 & WSA \\
\hline 150 & US-SRM & 31.8214 & -110.87 & WSA * \\
\hline 151 & US-Ton & 38.4316 & -120.97 & WSA * \\
\hline
\end{tabular}

*12 terrestrial biomes: Croplands (CRO), closed Shrublands (CSH), deciduous broadleaf forest (DBF), deciduous needleleaf forest (DNF), evergreen broadleaf forest (EBF), evergreen needleleaf forest (ENF), grasslands (GRA), mixed forests (MF), open shrublands (OSH), savannas (SAV), permanent wetlands (WET), and woody savannas (WSA). 
Table 2. The comparison between model GPP and EC-tower GPP at different scales (site scale, biome scale).

\begin{tabular}{|c|c|c|c|c|c|c|c|c|c|}
\hline & Slope & Intercept & $R^{2}$ & Slope & Intercept & $R^{2}$ & Slope & Intercept & $R^{2}$ \\
\hline & \multicolumn{3}{|c|}{ site_daily } & \multicolumn{3}{|c|}{ site_year } & \multicolumn{3}{|c|}{ site_years } \\
\hline EC-LUE & $0.76^{* *}$ & $0.25^{* *}$ & 0.61 & $0.83 *$ & $0.87^{*}$ & 0.74 & $0.95 *$ & 0.79 * & 0.81 \\
\hline VPM & $0.8^{* *}$ & $-0.18^{* *}$ & 0.60 & $0.93 *$ & $-0.27^{* *}$ & 0.71 & $0.98^{* *}$ & $-0.67 *$ & 0.81 \\
\hline CFIX & 0.71 & 0.77 & 0.48 & 0.77 & 0.53 & 0.69 & 0.84 & 0.17 & 0.79 \\
\hline MODIS & $0.69 *$ & $0.83 *$ & 0.57 & $0.76^{*}$ & 0.58 & 0.78 & 0.82 & 0.23 & 0.82 \\
\hline GR & 0.73 & 0.89 & 0.54 & $0.81 *$ & 0.55 & 0.73 & 0.89 & 0.18 & 0.82 \\
\hline VI & $0.77^{*}$ & $0.25^{* *}$ & 0.53 & 0.76 & 0.32 & 0.72 & $0.8^{*}$ & $0.13 *$ & 0.85 \\
\hline TG & 0.73 * & $0.58^{*}$ & 0.48 & $0.87^{* *}$ & $-0.01 * *$ & 0.73 & 0.96 & -0.39 & 0.8 \\
\hline AVM & 0.75 & 0.44 & 0.46 & $0.87^{*}$ & $-0.03^{* *}$ & 0.72 & $0.94 *$ & -0.38 * & 0.79 \\
\hline LUE-NDWI & $0.79^{* *}$ & $0.94 *$ & 0.68 & $1 * *$ & $0.3^{* *}$ & 0.75 & $1^{* *}$ & 0.38 * & 0.82 \\
\hline \multirow[t]{2}{*}{ LUE-EF } & $0.82^{* *}$ & 0.84 * & 0.74 & $1 * *$ & $0.32 * *$ & 0.85 & $1.06^{* *}$ & $0.06^{* *}$ & 0.97 \\
\hline & \multicolumn{3}{|c|}{ biome_daily } & \multicolumn{3}{|c|}{ biome_year } & \multicolumn{3}{|c|}{ biome_years } \\
\hline EC-LUE & $0.84^{* *}$ & $-0.05^{* *}$ & 0.73 & $0.84 *$ & $-0.07^{*}$ & 0.83 & $0.97^{* *}$ & $0.72 *$ & 0.94 \\
\hline VPM & $0.86^{* *}$ & $-0.58 *$ & 0.77 & $0.96^{* *}$ & $-0.68 *$ & 0.77 & $1.03 *$ & $-0.87^{*}$ & 0.96 \\
\hline CFIX & $0.76^{*}$ & $0.45 *$ & 0.76 & $0.79 *$ & $0.45 *$ & 0.76 & $0.83 *$ & $0.2 *$ & 0.92 \\
\hline MODIS & 0.75 * & 0.49 * & 0.75 & 0.79 * & 0.49 * & 0.75 & $0.82 *$ & $0.23^{* *}$ & 0.91 \\
\hline GR & $0.79 *$ & $0.57^{*}$ & 0.81 & $0.79 *$ & $0.58 *$ & 0.81 & $0.87 *$ & $0.27^{* *}$ & 0.89 \\
\hline VI & 0.82 & 0.03 & 0.8 & 0.88 & 0.33 & 0.8 & 0.79 & 0.17 & 0.87 \\
\hline TG & $0.82 * *$ & $0.19 * *$ & 0.78 & $0.88^{*}$ & $0.29^{* *}$ & 0.78 & $0.93^{* *}$ & $-0.15^{* *}$ & 0.89 \\
\hline AVM & $0.85 *$ & $0.06^{*}$ & 0.79 & $0.9^{*}$ & $0.26^{* *}$ & 0.79 & $0.91 *$ & $-0.14 *$ & 0.84 \\
\hline LUE-NDWI & $0.98^{* *}$ & $0.38^{* *}$ & 0.76 & $1.04^{* *}$ & $0.11^{* *}$ & 0.84 & $1.09^{* *}$ & $0.1^{* *}$ & 0.94 \\
\hline LUE-EF & $0.96^{*}$ & $0.49 *$ & 0.84 & $1.03 *$ & $0.15^{* *}$ & 0.88 & $1.08^{* *}$ & $0.02 * *$ & 0.97 \\
\hline
\end{tabular}

* represent that the slope and 1:1 line is significant within the $95 \%$ confidence interval, and ${ }^{* *}$ is significant within the $99 \%$ confidence interval.
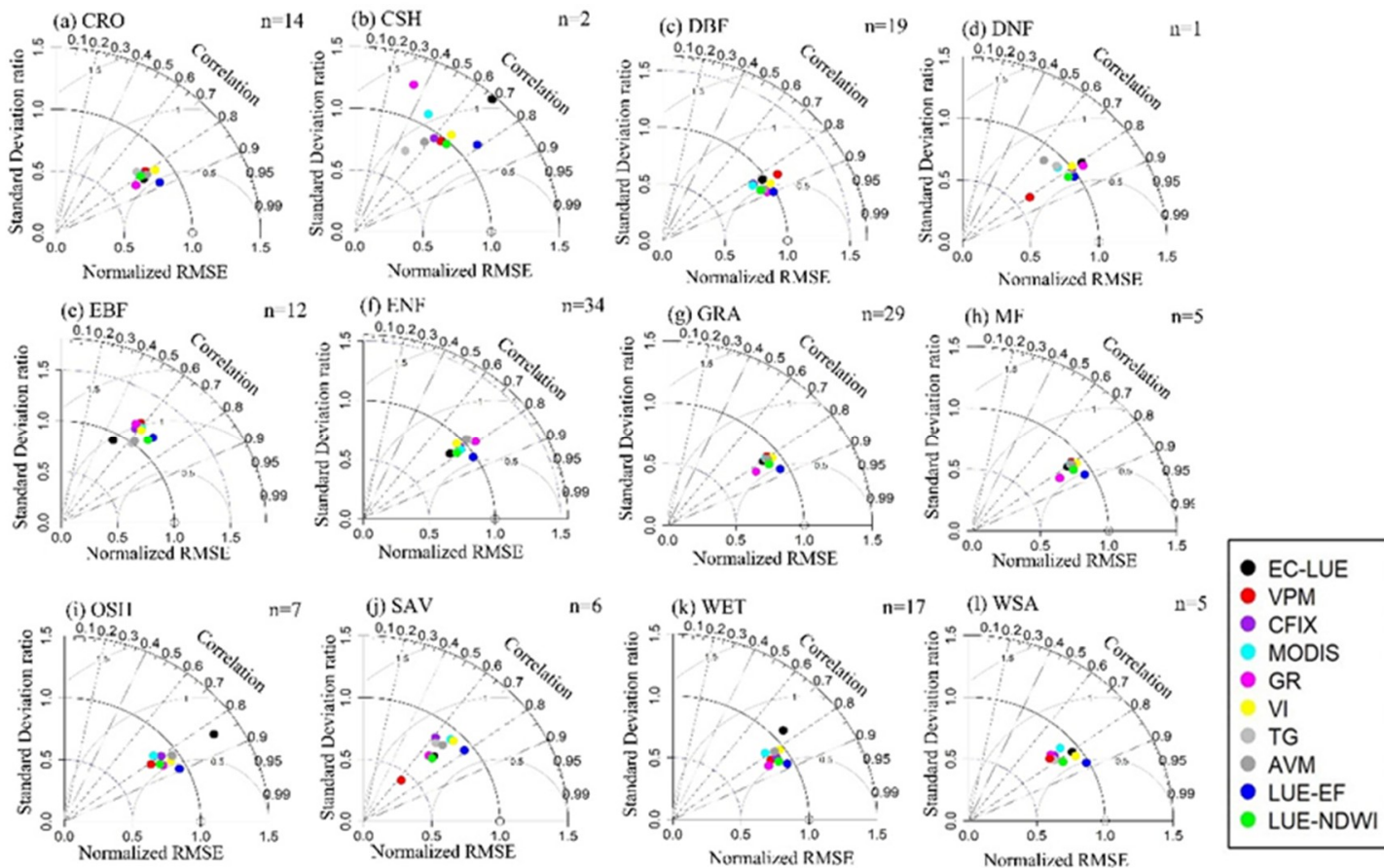

Figure A1. The Taylor diagram showing the overall performance of all models under different biomes. The color dots represent the models in the corresponding legend. The Taylor diagram is a polar graph in which the cosine of the angle between the X-axis is the correlation coefficient between the GPP of the model and EC-tower. The radial direction is the ratio of model to EC-tower GPP standard deviation. The grey arcs represent the RMSE normalized by standard deviation for each model. The $\mathrm{n}$ is the number of EC-towers. Where (a-i) contains 12 terrestrial biomes: CRO (croplands), CSH (closed Shrublands), DBF (deciduous broadleaf forest), DNF (deciduous needleleaf forest), EBF (evergreen broadleaf forest), ENF (evergreen needleleaf forest), GRA (grasslands), MF (mixed forests), OSH (open shrublands), SAV (savannas), WET (permanent wetlands), WSA (woody savannas). 

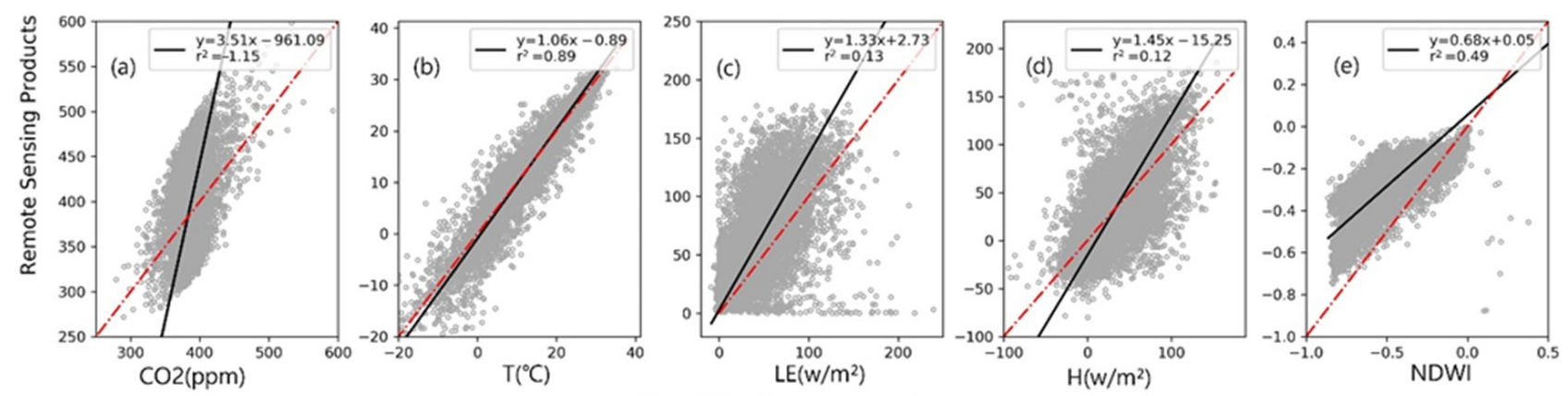

Flux Site Measurement

Figure A2. The comparison of remote sensing products data and ground EC-towers at site scale. The red dotted line is the 1:1 dotted line. Where (a) is $\mathrm{CO}_{2}(\mathrm{ppm}),(\mathbf{b})$ is $\mathrm{T}\left({ }^{\circ} \mathrm{C}\right),(\mathbf{c})$ is $\mathrm{LE}\left(\mathrm{w} / \mathrm{m}^{2}\right),(\mathbf{d})$ is $\mathrm{H}\left(\mathrm{w} / \mathrm{m}^{2}\right)$, and (e) is NDWI. It's worth noting that the NDWI data is based on a spatial NDWI (500 m resolution) and spatial NDWI (10 km resolution) of different spatial resolutions.
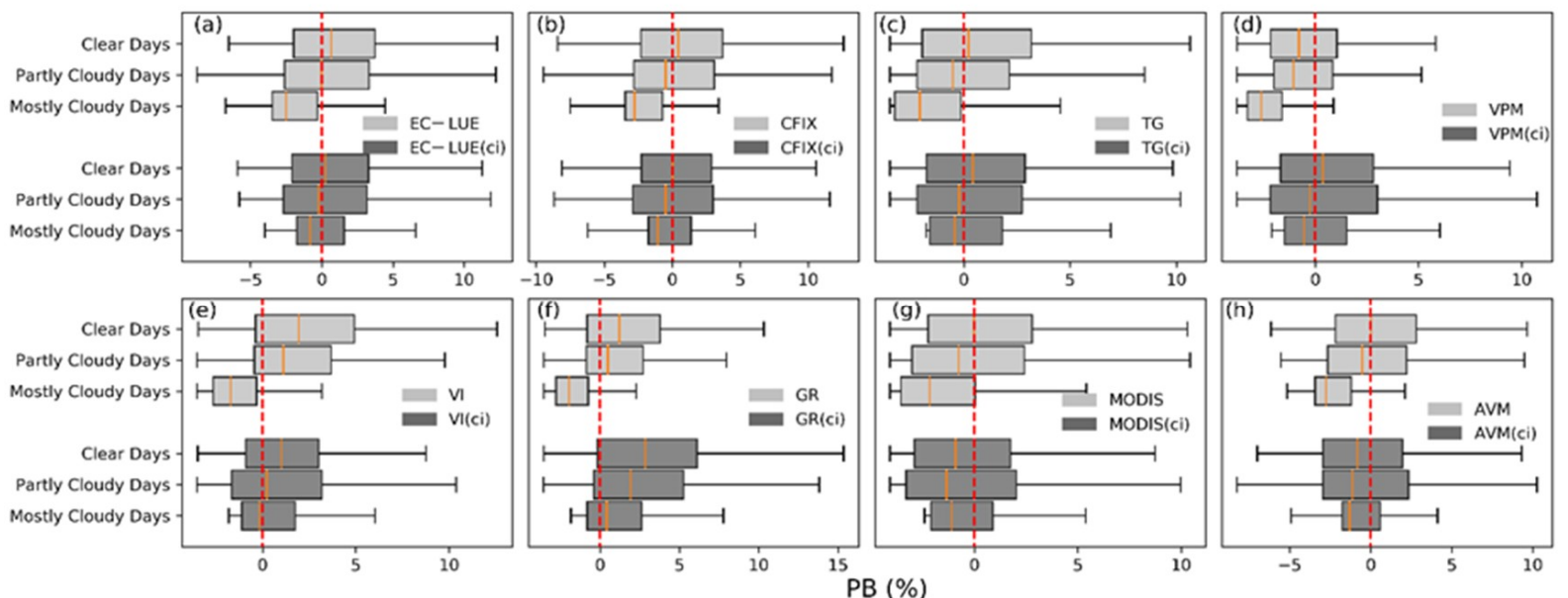

Figure A3. The deviation of the models under different cloud cover conditions. The light-colored part boxplots are the deviation statistics percentage bias (PB, \%) of the existing models' GPP predictions compared with the EC-tower GPP for each site under different cloud cover conditions. The dark part (ci) is the change after multiplying the result of each model by the cloud cover factor (F_CI), according to Equation (3). adding the cloud cover index (CI). The red dotted line denotes the line where $\mathrm{PB}=$ is equal to 0 , i.e., unbiased, and colored vertical line in boxplots are the means. Where (a) is EC-LUE (eddy covariance-light use efficiency model), (b) is CFIX (carbon fixation model), (c) is TG (temperature-greenness model), (d) is VPM (vegetation photosynthesis model), (e) is VI (vegetation-indices model), (f) is GR (green-ness-radiation model), (g) is MODIS (moderate resolution imaging spectroradiometer model), and (h) is AVM (alpine vegetation model).

\section{References}

1. Campbell, J.E.; Berry, J.A.; Seibt, U.; Smith, S.J.; Montzka, S.A.; Launois, T.; Belviso, S.; Bopp, T.L.S.B.L.; Laine, M. Large historical growth in global terrestrial gross primary production. Nature 2017, 544, 84-87. [CrossRef]

2. Schaefer, K.; Schwalm, C.R.; Williams, C.; Arain, M.A.; Barr, A.; Chen, J.M.; Davis, K.J.; Dimitrov, D.; Hilton, T.W.; Hollinger, D.Y.; et al. A model-Data comparison of gross primary productivity: Results from the North American Carbon Program site synthesis. J. Geophys. Res. Space Phys. 2012, 117, 1-15. [CrossRef]

3. Yi Zheng, Y.; Shen, R.; Wang, Y.; Li, X.; Liu, S.; Liang, S.; Chen, J.M.; Ju, W.; Hang, L.; Yuan, W. Improved estimate of global gross primary production for reproducing its long-Term variation, 1982-2017. Earth Syst. Sci. Data Discuss. 2019, 12, 2725-2746. [CrossRef]

4. Beer, C.; Reichstein, M.; Tomelleri, E.; Ciais, P.; Jung, M.; Carvalhais, N.; Rödenbeck, C.; Arain, M.A.; Baldocchi, D.; Bonan, G.B.; et al. Terrestrial gross carbon dioxide uptake: Global distribution and covariation with climate. Science 2010, 329, 834-838. [CrossRef] [PubMed] 
5. Xiao, J.; Chevallier, F.; Gomez, C.; Guanter, L.; Hicke, J.A.; Huete, A.R.; Ichii, K.; Ni, W.; Pang, Y.; Rahman, A.F. Remote sensing of the terrestrial carbon cycle: A review of advances over 50 years. Remote Sens. Environ. 2019, 233, 111383. [CrossRef]

6. Wang, H.; Prentice, I.C.; Keenan, T.F.; Davis, T.W.; Wright, I.J.; Cornwell, W.K.; Evans, B.J.; Peng, C. Towards a universal model for carbon dioxide uptake by plants. Nat. Plants 2017, 3, 734-741. [CrossRef]

7. Yuan, W.; Cai, W.; Xia, J.; Chen, J.; Liu, S.; Dong, W.; Merbold, L.; Law, B.; Arain, A.; Beringer, J.; et al. Global comparison of light use efficiency models for simulating terrestrial vegetation gross primary production based on the LaThuile database. Agric. For. Meteorol. 2014, 192-193, 108-120. [CrossRef]

8. Wagle, P.; Gowda, P.H.; Xiao, X.; Anup, K.C. Parameterizing ecosystem light use efficiency and water use efficiency to estimate maize gross primary production and evapotranspiration using MODIS EVI. Agric. For. Meteorol. 2016, 222, 87-97. [CrossRef]

9. Xiao, X.; Hollinger, D.; Aber, J.; Goltz, M.; Davidson, E.A.; Zhang, Q.; Moore, B. Satellite-Based modeling of gross primary production in an evergreen needleleaf forest. Remote Sens. Environ. 2004, 89, 519-534. [CrossRef]

10. Yuan, W.; Liu, S.; Zhou, G.; Zhou, G.; Tieszen, L.L.; Baldocchi, D.; Bernhofer, C.; Gholz, H.; Goldstein, A.H.; Goulden, M.L.; et al. Deriving a light use efficiency model from eddy covariance flux data for predicting daily gross primary production across biomes. Agric. For. Meteorol. 2007, 143, 189-207. [CrossRef]

11. Xiao, Z.; Liang, S.; Wang, J.; Xiang, Y.; Zhao, X.; Song, J. Long-Time-Series global land surface satellite leaf area index product derived from MODIS and AVHRR Surface Reflectance. IEEE Trans. Geosci. Remote Sens. 2016, 54, 5301-5318. [CrossRef]

12. Xiao, X.; Zhang, Q.; Braswell, B.; Urbanski, S.; Boles, S.; Wofsy, S.; Moore, B.; Ojima, D. Modeling gross primary production of temperate deciduous broadleaf forest using satellite images and climate data. Remote Sens. Environ. 2004, 91, 256-270. [CrossRef]

13. Zheng, Y.; Zhang, L.; Xiao, J.; Yuan, W.; Yan, M.; Li, T.; Zhang, Z. Sources of uncertainty in gross primary productivity simulated by light use efficiency models: Model structure, parameters, input data, and spatial resolution. Agric. For. Meteorol. 2018, 263, 242-257. [CrossRef]

14. Yuan, W.; Chen, Y.; Xia, J.; Dong, W.; Magliulo, V.; Moors, E.; Olesen, J.E.; Zhang, H. Estimating crop yield using a satellite-Based light use efficiency model. Ecol. Indic. 2016, 60, 702-709. [CrossRef]

15. Xie, X.; Li, A.; Tan, J.; Jin, H.; Nan, X.; Zhang, Z.; Bian, J.; Lei, G. Assessments of gross primary productivity estimations with satellite data-Driven models using eddy covariance observation sites over the northern hemisphere. Agric. For. Meteorol. 2020, 280, 107771. [CrossRef]

16. Yuan, W.; Cai, W.; Nguy-Robertson, A.L.; Fang, H.; Suyker, A.E.; Chen, Y.; Dong, W.; Liu, S.; Zhang, H. Uncertainty in simulating gross primary production of cropland ecosystem from satellite-Based models. Agric. For. Meteorol. 2015, 207, 48-57. [CrossRef]

17. Wang, H.; Jia, G.; Fu, C.; Feng, J.; Zhao, T.; Ma, Z. Deriving maximal light use efficiency from coordinated flux measurements and satellite data for regional gross primary production modeling. Remote Sens. Environ. 2010, 114, 2248-2258. [CrossRef]

18. Xiao, J.; Davis, K.J.; Urban, N.M.; Keller, K.; Saliendra, N.Z. Upscaling carbon fluxes from towers to the regional scale: Influence of parameter variability and land cover representation on regional flux estimates. J. Geophys. Res. 2011, 116, 1-15. [CrossRef]

19. Badgley, G.; Anderegg, L.D.L.; Berry, J.A.; Field, C.B. Terrestrial gross primary production: Using NIRV to scale from site to globe. Glob. Chang. Biol. 2019, 25, 3731-3740. [CrossRef]

20. Majasalmi, T.; Stenberg, P.; Rautiainen, M. Comparison of ground and satellite-Based methods for estimating stand-Level fPAR in a boreal forest. Agric. For. Meteorol. 2017, 232, 422-432. [CrossRef]

21. Sasai, T.; Okamoto, K.; Hiyama, T.; Yamaguchi, Y. Comparing terrestrial carbon fluxes from the scale of a flux tower to the global scale. Ecol. Model. 2007, 208, 135-144. [CrossRef]

22. Gomis-cebolla, J.; Jimenez, J.C.; Sobrino, J.A. Remote Sensing of Environment LST retrieval algorithm adapted to the Amazon evergreen forests using MODIS data. Remote Sens. Environ. 2017, 204, 401-411. [CrossRef]

23. Foga, S.; Scaramuzza, P.L.; Guo, S.; Zhu, Z.; Dilley, R.D.; Beckmann, T.; Schmidt, G.L.; Dwyer, J.L.; Hughes, M.J.; Laue, B. Cloud detection algorithm comparison and validation for operational Landsat data products. Remote Sens. Environ. 2017, 194, 379-390. [CrossRef]

24. Stillinger, T.; Roberts, D.A.; Collar, N.M.; Dozier, J. Cloud masking for Landsat 8 and MODIS Terra over snow covered terrain: Error analysis and spectral similarity between snow and cloud. Water Resour. Res. 2019, 55, 6169-6184. [CrossRef] [PubMed]

25. Wu, C.; Chen, J.M.; Desai, A.R.; Hollinger, D.Y.; Arain, M.A.; Margolis, H.A.; Gough, C.; Staebler, R.M. Remote sensing of canopy light use efficiency in temperate and boreal forests of North America using MODIS imagery. Remote Sens. Environ. 2012, 118, 60-72. [CrossRef]

26. Sims, D.A.; Rahman, A.F.; Cordova, V.D.; El-Masri, B.Z.; Baldocchi, D.D.; Bolstad, P.V.; Flanagan, L.B.; Goldstein, A.H.; Hollinger, D.Y.; Misson, L.; et al. A new model of gross primary productivity for North American ecosystems based solely on the enhanced vegetation index and land surface temperature from MODIS. Remote Sens. Environ. 2008, 112, 1633-1646. [CrossRef]

27. Veroustraete, F.; Sabbe, H.; Eerens, H. Estimation of carbon mass fluxes over Europe using the C-Fix model and Euroflux data. Remote Sens. Environ. 2002, 83, 376-399. [CrossRef]

28. Gitelson, A.A.; Viña, A.; Verma, S.B.; Rundquist, D.; Arkebauer, T.J.; Keydan, G.; Leavitt, B.; Ciganda, V.; Burba, G.G.; Suyker, A.E. Relationship between gross primary production and chlorophyll content in crops: Implications for the synoptic monitoring of vegetation productivity. J. Geophys. Res. 2006, 111, 1-13. [CrossRef]

29. Liu, Z.; Wang, L.; Wang, S. Comparison of different GPP models in China using MODIS image and ChinaFLUX data. Remote Sens. Sens. 2014, 6, 10215-10231. [CrossRef] 
30. Running, S.T.; Nemani, R.R.; Heinsch, F.A.; Zhao, M.; Reeves, M. A Continuous Satellite-Derived Measure of Global Terrestrial Primary Production. Bioscience 2006, 54, 547-560. [CrossRef]

31. Wu, C.; Munger, J.W.; Niu, Z.; Kuang, D. Comparison of multiple models for estimating gross primary production using MODIS and eddy covariance data in Harvard Forest. Remote Sens. Environ. 2010, 114, 2925-2939. [CrossRef]

32. Gu, L.; Baldocchi, D.D.; Wofsy, S.C.; Munger, J.W.; Michalsky, J.J.; Urbanski, S.P.; Boden, T.A. Response of a Deciduous Forest to the Mount Pinatubo Eruption: Enhanced Photosynthesis. Science 2003, 299, 2035-2038. [CrossRef] [PubMed]

33. Kicklighter, D.W. A first-Order analysis of the potential rôle of $\mathrm{CO} 2$ fertilization to affect the global carbon budget: A comparison of four terrestrial biosphere models. Tellus B: Chem. Phys. Meteorol. 1999, 51, 343-366. [CrossRef]

34. Raich, J.W.; Rastetter, E.B.; Melillo, J.M.; Kicklighter, D.W.; Steudler, P.A.; Peterson, B.J.; Grace, A.L.; Moore, B.; Vorosmarty, C.J. Potential Net Primary Productivity in South America: Application of a Global Model. Ecol. Appl. 2013, 1, 399-429. [CrossRef] [PubMed]

35. Murphy, R.J.; Whelan, B.; Chlingaryan, A.; Sukkarieh, S. Quantifying leaf scale variations in water absorption in lettuce from hyperspectral imagery: A laboratory study with implications for measuring leaf water content in the context of precision agriculture. Precis. Agric. 2018, 767-787. [CrossRef]

36. Ding, C.; Liu, X.; Huang, F.; Li, Y.; Zou, X. Onset of drying and dormancy in relation to water dynamics of semi-arid grasslands from MODIS NDWI. Agric. For. Meteorol. 2017, 234-235, 22-30. [CrossRef]

37. Pastorello, G.; Trotta, C.; Canfora, E.; Chu, H.; Christianson, D.; Frank, J.; Frank, J.; Massman, M.; Urbanski, S. The FLUXNET2015 dataset and the ONEFlux processing pipeline for eddy covariance data. Sci. Data 2020, 7, 225. [CrossRef]

38. Baty, F.; Ritz, C.; Charles, S.; Brutsche, M. A toolbox for nonlinear regression in R: The package nls tools. J. Stat. Softw. 2015, 66, 1-21. [CrossRef]

39. Zhang, F.; Shi, X.; Zeng, C.; Wang, L.; Xiao, X.; Wang, G.; Chen, Y.; Zhang, H.; Lu, X.; Immerzeel, W. Recent stepwise sediment flux increase with climate change in the Tuotuo River in the central Tibetan Plateau. Sci. Bull. 2020, 65, 410-418. [CrossRef]

40. Carroll, R.J.; Ruppert, D. The Use and Misuse of Orthogonal Regression in Linear Errors-in-Variables Models. General 2014, 50, 1-6.

41. Piñeiro, G.; Perelman, S.; Guerschman, J.P.; Paruelo, J.M. How to evaluate models: Observed vs. predicted or predicted vs. observed? Ecol. Model. 2008, 216, 316-322. [CrossRef]

42. Leng, L.; Zhang, T.; Kleinman, L.; Zhu, W. Ordinary least square regression, orthogonal regression, geometric mean regression and their applications in aerosol science. J. Phys. Conf. Ser. 2007, 78, 24-28. [CrossRef]

43. Valbuena, R.; Hernando, A.; Manzanera, J.; Görgens, E.; Almeida, D.; Mauro, F.; García-Abril, A.; Coomes, D. Enhancing of accuracy assessment for forest above-Ground biomass estimates obtained from remote sensing via hypothesis testing and overfitting evaluation. Ecol. Model. 2017, 366, 15-26. [CrossRef]

44. Forzieri, G. Increased control of vegetation on global terrestrial energy fluxes. Nat. Clim. Chang. 2020, 10, 356-362. [CrossRef]

45. Running, S.W.; Zhao, M. Daily GPP and Annual NPP (MOD17A2/A3) products NASA Earth Observing System MODIS Land Algorithm-User's guide V3. General 2015, 28, 1-6.

46. Keenan, T.F.; Prentice, I.C.; Canadell, J.G.; Williams, A.C.; Wang, H.; Raupach, M.; Collatz, G.J. Recent pause in the growth rate of atmospheric CO2 due to enhanced terrestrial carbon uptake. Nat. Commun. 2016, 7, 1-9. [CrossRef]

47. Jung, M.; Schwalm, C.; Migliavacca, M.; Walther, S.; Camps-Valls, G.; Koirala, S.; Anthoni, P.; Besnard, S.; Bodesheim, P.; Carvalhais, N.; et al. Scaling carbon fluxes from eddy covariance sites to globe: Synthesis and evaluation of the FLUXCOM approach. Biogeosciences 2020, 17, 1343-1365. [CrossRef]

48. Kondo, M.; Ichii, K.; Takagi, H.; Sasakawa, M. Comparison of the data-Driven top-Down and bottom-Up global terrestrial CO2 exchanges: GOSAT CO2 inversion and empirical eddy flux upscaling. J. Geophys. Res. Biogeosci. 2015, 120, 1226-1245. [CrossRef]

49. Jiang, C.; Ryu, Y. Remote Sensing of Environment Multi-Scale evaluation of global gross primary productivity and evapotranspiration products derived from Breathing Earth System Simulator (BESS). Remote Sens. Environ. 2016, 186, 528-547. [CrossRef]

50. Upadhyaya, S.A.; Kirstetter, P.-E.; Gourley, J.J.; Kuligowski, R.J. On the Propagation of Satellite Precipitation Estimation Errors: From Passive Microwave to Infrared Estimates. Estimates. J. Hydrometeorol. 2020, 21, 1367-1381. [CrossRef]

51. Cheng, S.J.; Butterfield, Z.; Keppel-Aleks, G.; Steiner, A.L. The Global Influence of Cloud Optical Thickness on Terrestrial Carbon Uptake. Earth Interact. 2019, 23, 1-22.

52. Haverd, V.; Smith, B.; Canadell, J.G.; Cuntz, M.; Mikaloff-Fletcher, S.; Farquhar, G.D.; Woodgate, W.; Briggs, P.R.; Trudinger, C.M. Higher than expected CO 2 fertilization inferred from leaf to global observations. Glob. Chang. Biol. 2020, 26, $2390-2402$. [CrossRef] [PubMed]

53. Smith, W.K.; Reed, S.C.; Cleveland, C.C.; Ballantyne, A.P.; Anderegg, W.R.L.; Wieder, W.R.; Liu, Y.Y.; Running, S.W. Large divergence of satellite and Earth system model estimates of global terrestrial CO2 fertilization. Nat. Clim. Chang. 2016, 6, 306-310. [CrossRef]

54. Chen, Y.; Xia, J.; Liang, S.; Feng, J.; Fisher, J.B.; Li, X.; Li, X.; Liu, S.; Ma, Z.; Miyata, A.; et al. Comparison of satellite-based evapotranspiration models over terrestrial ecosystems in China. Remote Sens. Environ. 2014, 140, 279-293. [CrossRef]

55. Ma, H.Y. CAUSES: On the Role of Surface Energy Budget Errors to the Warm Surface Air Temperature Error Over the Central United States. J. Geophys. Res. Atmos. 2018, 123, 2888-2909. [CrossRef]

56. Gao, B.-C. NDWI-A normalized difference Water index for remote sensing of vegetation liquid water from space. Remote Sens. Environ. 1996, 266, 257-266. [CrossRef] 
57. Keppel-Aleks, G.; Washenfelder, R.A. The effect of atmospheric sulfate reductions on diffuse radiation and photosynthesis in the United States during 1995-2013. Geophys. Res. Lett. 2016, 43, 9984-9993. [CrossRef]

58. Lee, M.S.; Hollinger, D.Y.; Keenan, T.F.; Ouimette, A.P. Agricultural and Forest Meteorology Model-based analysis of the impact of di ff use radiation on CO 2 exchange in a temperate deciduous forest. Agric. For. Meteorol. 2018, 249, 377-389. [CrossRef]

59. Sun, Z.; Wang, X.; Zhang, X.; Tani, H.; Engliang, G.; Shuai, Y.; Zhang, T. Science of the Total Environment Evaluating and comparing remote sensing terrestrial GPP models for their response to climate variability and $\mathrm{CO}_{2}$ trends. Sci. Total Environ. 2019, 668, 696-713. [CrossRef]

60. Xie, X.; Li, A. Development of a topographic-Corrected temperature and greenness model (TG) for improving GPP estimation over mountainous areas. Agric. For. Meteorol. 2020, 295, 108193. [CrossRef]

61. Zhang, Z.; Zhang, Y.; Zhang, Y.; Chen, J.M. Correcting Clear-Sky Bias in Gross Primary Production Modeling From Satellite Solar-Induced Chlorophyll Fluorescence Data. J. Geophys. Res. Biogeosci. 2020, 125, e2020JG005822. [CrossRef]

62. Flack-Prain, S.; Meir, P.; Malhi, Y.; Smallman, T.; Williams, M. The importance of physiological, structural and trait responses to drought stress in driving spatial and temporal variation in GPP across Amazon forests. Biogeosciences 2019, 16, 4463-4484. [CrossRef]

63. Ren, Y.; Zhang, F.; Kung, H.-T.; Johnson, V.C.; Wang, J.; Zhang, Y.; Yu, H.; Yushanjiang, A. Using the vegetation-solar radiation (VSr) model to estimate the short-term gross primary production (GPP) of vegetation in Jinghe county, XinJiang, China. Ecol. Eng. 2017, 107, 208-215. [CrossRef] 